\title{
Effect of temperature on zooplankton vertical migration velocity
}

\author{
Stefano Simoncelli $\mathbb{D} \cdot$ Stephen J. Thackeray $\cdot$ Danielle J. Wain
}

Received: 19 January 2018/Revised: 2 November 2018/ Accepted: 6 November 2018/Published online: 19 November 2018 (C) The Author(s) 2018

\begin{abstract}
Zooplankton diel vertical migration (DVM) is an ecologically important process, affecting nutrient transport and trophic interactions. Available measurements of zooplankton displacement velocity during the DVM in the field are rare; therefore, it is not known which factors are key in driving this velocity. We measured the velocity of the migrating layer at sunset (upward bulk velocity) and sunrise (downwards velocity) in summer 2015 and 2016 in a lake using the backscatter strength (VBS) from an acoustic Doppler current profiler. We collected time series of temperature, relative change in light intensity chlorophyll$a$ concentration and zooplankton concentration. Our data show that upward velocities increased during the summer and were not enhanced by food, light intensity
\end{abstract}

Handling editor: Karl Havens

Electronic supplementary material The online version of this article (https://doi.org/10.1007/s10750-018-3827-1) contains supplementary material, which is available to authorized users.

S. Simoncelli $(\bowtie) \cdot$ D. J. Wain

Department of Architecture and Civil Environmental Engineering, University of Bath, Claverton Down,

Bath BA2 7AY, UK

e-mail: simoncelli@igb-berlin.de

\section{S. J. Thackeray}

Centre for Ecology \& Hydrology, Lancaster Environment Centre, Library Avenue, Bailrigg, Lancaster LA1 4AP, UK or by VBS, which is a proxy for zooplankton concentration and size. Upward velocities were strongly correlated with the water temperature in the migrating layer, suggesting that temperature could be a key factor controlling swimming activity. Downward velocities were constant, likely because Daphnia passively sink at sunrise, as suggested by our model of Daphnia sinking rate. Zooplankton migrations mediate trophic interactions and web food structure in pelagic ecosystems. An understanding of the potential environmental determinants of this behaviour is therefore essential to our knowledge of ecosystem functioning.

Keywords Chlorophyll- $a$. Displacement velocity . ADCP · Turbulence · Daphnia - Volume backscatter strength $\cdot$ Diel vertical migration

\section{Introduction}

Zooplankton diel vertical migration (DVM) is an ecologically important process, driven by internal and external drivers, and affecting nutrient transport and trophic interactions in lakes and oceans (Hays, 2003; Ringelberg, 2010). In a typical DVM, organisms migrate from deep and cold waters towards the warmer surface at sunset, and they descend at sunrise (Ringelberg, 2010; Williamson et al., 2011). 
Predation, light, food availability, and temperature are recognised as the main DVM drivers. However, avoidance of visually hunting juvenile fish and food requirements are generally considered the most significant factors (Ringelberg, 1999; Hays, 2003; Van Gool \& Ringelberg, 2003; Williamson et al., 2011). According to this reasoning, zooplankton hide during the daytime in the deep and dark layers of the lake in response to chemical cues released by fish (kairomones) (Dodson, 1988; Neill, 1990; Loose \& Dawidowicz, 1994; Lass \& Spaak, 2003; Boeing et al., 2003; Beklioglu et al., 2008; Cohen \& Forward, 2009). At night, when mortality risk from visual predators is low, zooplankton migrate to surface waters to graze on abundant phytoplankton. Food availability can modify migration behaviour as well (Van Gool \& Ringelberg, 2003); if a deep chlorophyll maximum is present, zooplankton may not migrate (Rinke \& Petzoldt, 2008). Finally, DVM can still take place in very transparent and fish-less lakes where zooplankton hide to prevent damage from surface UV radiation (Williamson et al., 2011; Tiberti \& Iacobuzio, 2013; Leach et al., 2014).

Several laboratory (Daan \& Ringelberg, 1969; Van Gool \& Ringelberg, 1998a, b; Ringelberg, 1999; Van Gool \& Ringelberg, 2003) and field observations (Ringelberg \& Flik, 1994) suggest that the speed at which zooplankton migrate is influenced by the drivers affecting the DVM. Variations in this velocity have been used as a proxy to infer possible reactions and behavioural changes in zooplankton populations. This speed has two components: (1) the swimming velocity (SV), which is the organism's instantaneous velocity during a reactive phase (Ringelberg, 2010); and (2) the displacement velocity (DV), which is the vertical displacement of the organism divided by the time taken to perform the movement (Gool \& Ringelberg, 1995). The DV is smaller than SV because it combines various animal reactions, including latent periods.

The dependence of the zooplankton SV on the presence of predators in the water column is species specific. Beck \& Turingan (2007) showed that the swimming speed of brine shrimp (Artemia franciscana Kellog, 1906) and two copepod species (Nitokra lacustris Schmankevitsch, 1875 and Acartia tonsa Dana, 1849) increased when zooplankton are exposed to water with larval fish. However, this was not the case for the rotifer Brachionus rotundiformis
Tschugunoff, 1921. Dodson et al. (1995) hypothesised instead that Daphnia may adopt a conservativeswimming behaviour, because faster swimming velocity would increase predator-prey encounter rates and therefore predation risk. In their experiment, they did not observe increases in SV of Daphnia pulex Leydig, 1860 when exposed to Chaoborus-enriched water. However, Weber \& Van Noordwijk (2002) later showed that the swimming response of Daphnia galeata Sars, 1864 to info-chemicals can be clonespecific and that Perca kairomone can positively affect their speed. Finally, Van Gool \& Ringelberg (1998a, b, 2003) observed that the Daphnia swimming response to changes in light intensity $(S)$ can be enhanced by chemical signals from Perca fluviatilis Linnaeus, 1758 and by food concentration as well. Field observations, by Ringelberg et al. (1991) and Ringelberg and Flik (1994), showed instead that the DV at dusk of Daphnia galeata $x$ hyalina was well correlated with $S$ measured in the water column at the time of the migration. The response of the animals was strongly light-driven but not influenced by food concentration or water transparency. Moreover, acceleration and deceleration in $S$ can also play a role in determining the Daphnia swimming response (Van Gool, 1997).

Laboratory observations have shown that organism swimming speed can also be greatly enhanced upon exposure to higher water temperatures. Temperature has a twofold effect. Warmer water enhances the biological and metabolic activity of organisms, increasing energy available for locomotion and therefore the power available for thrust generation (Beveridge et al., 2010; Moison et al., 2012; Humphries, 2013; Jung et al., 2014). At the same time, a higher water temperature reduces fluid kinematic viscosity (v) and drag on zooplankton beating appendages, so that they can swim faster (Machemer, 1972; Larsen et al., 2008; Larsen \& Riisgård, 2009; Moison et al., 2012). Since this temperature-dependant behaviour has never been demonstrated in the field and during the DVM, it is not known whether this may be relevant during the vertical ascent.

Turbulence in the environment can also strongly affect zooplankton motility during the DVM. Organisms usually avoid highly energetic environments if turbulence negatively affects their behaviour (Visser \& Stips, 2002; Prairie et al., 2012; Saiz et al., 2013; Wickramarathna, 2016). Some zooplankton species 
are able to maintain their swimming velocity (Michalec et al., 2015) or overcome turbulent eddies (Seuront et al., 2004; Webster et al., 2015; Wickramarathna, 2016). Finally, zooplankton swimming velocity may also be size-dependent; larger organisms can propel themselves faster (Gries et al., 1999; Huntley \& Zhou, 2004; Andersen Borg et al., 2012; Wickramarathna et al., 2014) because of their larger swimming appendages.

With regard to the downwards DVM at sunrise, the zooplankton velocity may vary greatly depending on the swimming behaviour adopted by the organism. Descent can occur by active swimming, when organisms orient downwards, or by passive sinking (Dodson et al., 1997b; Ringelberg, 2010) with lower velocities controlled by organism's buoyancy and gravity. To date, little is known about which parameters really affect the choice of a swimming behaviour and velocity. The only available study is by Ringelberg \& Flik (1994) who reported that Daphnia swim downwards only when the light stimulus $S$ is high but this threshold is currently not known. However, no evidence was provided that the organisms really sank.

Available measurements of zooplankton swimming velocity during the DVM in the field are rare. The first estimates of zooplankton DV were made by Ringelberg \& Flik (1994) using successive net hauls to measure the zooplankton position in the water column. This method only offers a coarse resolution of the organisms position and is time-consuming. More recent studies by Lorke et al. (2004) and Huber et al. (2011) instead measured the DV using velocity data and variations in the backscatter strength signal from an Acoustic Current Doppler Profiler (ADCP). However, their objective was not to analyse variations in time series of the zooplankton DV.

The objectives of this study were (1) to explore and explain for the first time seasonal variability in the DV of diel migration in the field; and (2) to understand which environmental parameters really drive the rate of zooplankton migration under real field conditions, when combined DVM drivers act at the same time. Existing studies compared only the effect of one parameter at the time on the DV and assessed the zooplankton behaviour only with light-induced swimming responses. In this study, we continuously measured the velocity of the migrating layer (bulk velocity or mean DV) at sunset and sunrise along with the following DVM drivers measured in the field: water temperature, turbulence, chlorophyll- $a$ concentration, light conditions, and zooplankton concentration and size during the DVM. We quantified $v_{\text {up }}$ as the bulk velocity at dusk, when zooplankton actively swim to reach the surface, and employed a correlative approach to infer the likely dependence of $v_{\text {up }}$ upon potential DVM drivers. At sunrise, when organisms usually sink towards the aphotic lake layer, the mean DV is referred as $v_{\text {down }}$. This velocity was modelled and correlated with zooplankton density and size measured in the laboratory to verify whether organisms sank.

\section{Materials and methods}

Field observations

\section{Study site}

Measurements were taken in 2015 and 2016 in Vobster Quay, a shallow man-made lake located in Radstock, UK. The lake has an average depth of $15 \mathrm{~m}$ and maximum depth of $40 \mathrm{~m}$ (see Fig. 1). It has a simple bathymetry, with very steep shores and a flat bottom. The lake is oligotrophic, with an average chlorophyll- $a$ concentration of about $1 \mu \mathrm{g} 1^{-1}$. During summer stratification, the surface temperature reaches a maximum of $21^{\circ} \mathrm{C}$, and the bottom temperature is approximately $9^{\circ} \mathrm{C}$. The metalimnion usually extends from 5 to $17 \mathrm{~m}$. The water transparency is very high, with an average Secchi depth of $10 \mathrm{~m}$ over the summer. The lake was stocked in August 2004 with a population of $P$. fluviatilis and Rutilus rutilus Linnaeus, 1758 .

\section{Acoustic measurements}

Acoustic measurements were employed to track the position of the zooplankton layer during the DVM (e.g. Lorke et al., 2004) and to estimate their DV at sunset and sunrise using the acoustic backscatter strength. An acoustic Doppler current profiler (ADCP, Signature $500 \mathrm{kHz}$ by Nortek) was bottom-deployed at location "A" in Fig. 1. The device was set up to record the acoustic backscatter strength (BS) from the vertical beam every $180 \mathrm{~s}$ for $90 \mathrm{~s}$ with a frequency of $0.5 \mathrm{~Hz}$. The BS $1 \mathrm{~m}$ below the surface and above the 


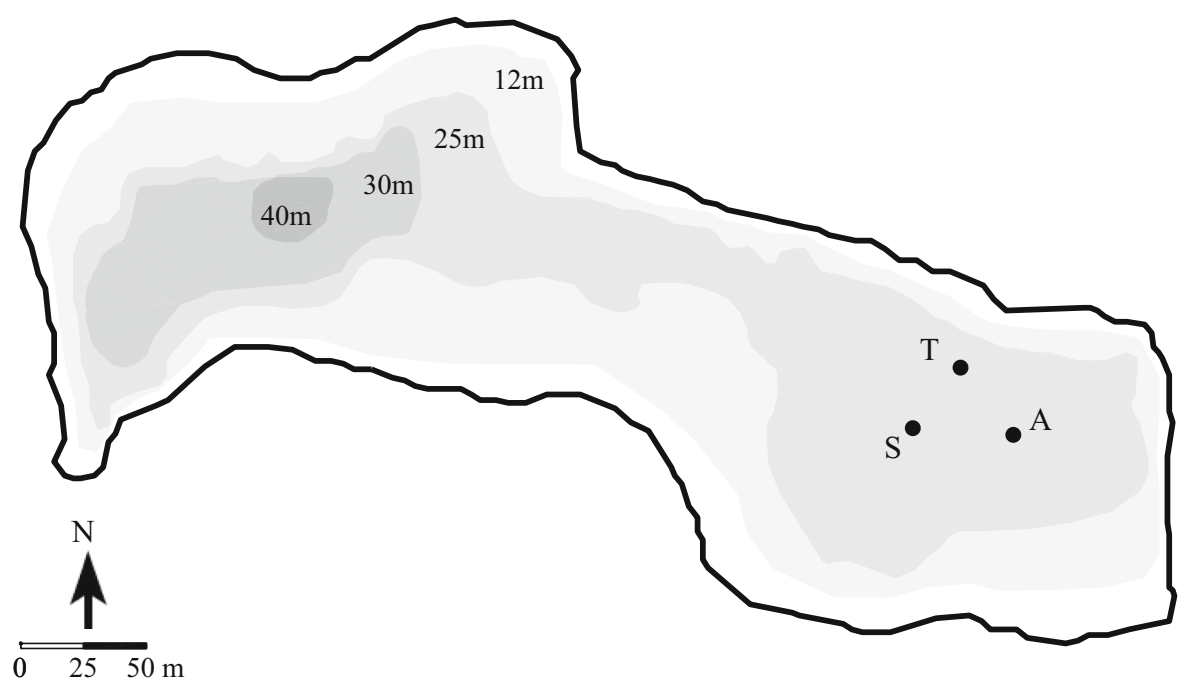

Fig. 1 Bathymetry of Vobster Quay. "S" denotes the sampling station where measurements were taken. "T" and "A" indicate the locations of the thermistor chain and ADCP, respectively

bottom was removed due to surface reflection and the ADCP blanking distance. Data were available from 7 July to 27 July 2015, 24 June to 7 July 2016, and 21 July to 19 August 2016.

The BS was then converted to the relative volume backscatter strength (VBS) to account for any transmission loss of the intensity signal, using the sonar equation (Deines, 1999):

$$
\mathrm{VBS}=\mathrm{BS}-P_{\mathrm{dbw}}-L_{\mathrm{dbm}}+2 \cdot \alpha \cdot R+20 \log _{10} \cdot R
$$

where $P_{\mathrm{dbw}}$ is the transmitted power sent in the water, $L_{\mathrm{dbm}}$ the $\log 10$ of the transmit pulse length $P=0.5 \mathrm{~m}$ (Nortek, pers. comm.) and $R$ the slant acoustic range. $\alpha$ is the acoustic absorption coefficient estimated following Francois (1982) and using the temperature profiles from the thermistors chain ("T" in Fig. 1).

\section{Bulk velocity estimation}

The bulk velocity of the migrating layer is defined as the slope of the zooplankton layer during the DVM. Fig. $2 \mathrm{~d}$ shows an example of the migration on 2 July 2016, where the VBS in black depicts the zooplankton in the water column. When the zooplankton start swimming upwards after sunset (21:45 local time), a line can be fit to the migrating layer, whose slope is constant throughout the ascending phase (red line in Fig. 2d). This slope is the upward bulk velocity ( $\left.v_{\text {up }}\right)$ and provides the mean DV of the organisms. The bulk velocity during the reverse DVM is referred as $v_{\text {down }}$.

To objectively and automatically estimate $v_{\text {up }}$ and $v_{\text {down }}$ from the VBS data, an image-detection algorithm was developed in MATLAB to detect the acoustic shape of the zooplankton layer and to estimate its slope. Two input parameters need to be provided by the user: (1) the box (target area) containing the layer and delimited by $\mathrm{Z}_{\text {WINDOw }}$ and $\mathrm{T}_{\text {WINDOw limits (see Fig. 2a); when the DVM begins }}$ and ends and its limits can be immediately identified from the acoustic image; (2) the VBS range $V_{\text {range }}=$ $\left[V_{\min }, V_{\max }\right]$ of the zooplankton in the migrating layer. This range is characteristic of the zooplankton for that day and is affected by the organism abundance and size. Because the VBS always reaches the maximum in the migrating layer, the algorithm can be controlled just by adjusting the lower limit $V_{\min }$ and setting $V_{\max }$ to the observed maximum of $85 \mathrm{~dB}$.

Once these two groups of parameters are set, to detect the layer, the algorithm picks the points in the target area where $V_{\min } \leq V B S \leq 85 \mathrm{~dB}$ (see red dots in Fig. 2b). The acoustic shape then can be identified by selecting the outer points of the layer (Fig. 2c). A line can be finally fitted to the red points to estimate $v_{\text {up }}$. Fig. $2 \mathrm{~d}$ shows $v_{\mathrm{up}, 81}=2.43 \mathrm{~mm} \mathrm{~s}^{-1}$ for $V_{\min }=81 \mathrm{~dB}$.

Some of the VBS data, representing isolated patches of zooplankton or environmental noise within the target area, had to be manually removed. An 

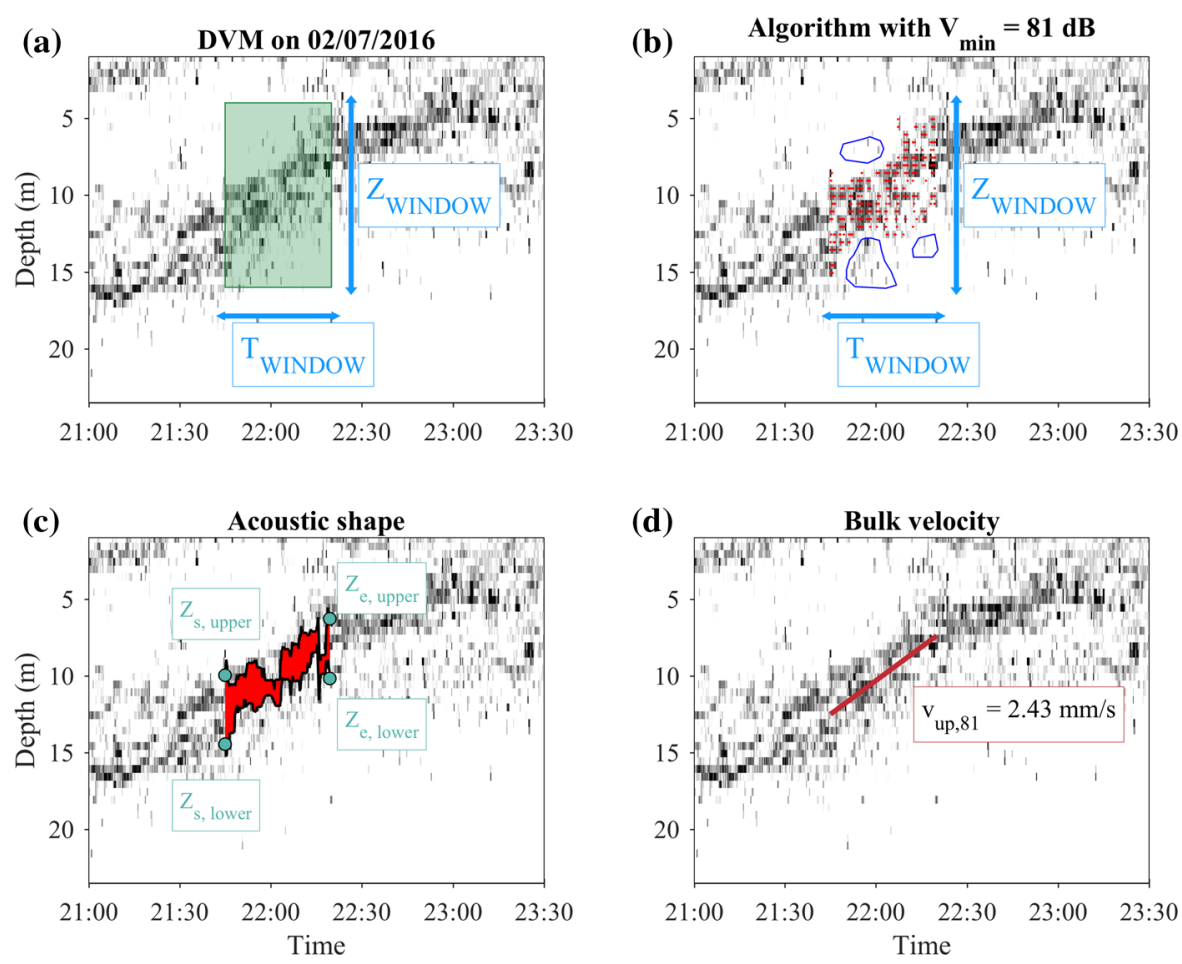

Fig. 2 Schematic of how the algorithm computes the bulk velocity. The four panels show the DVM captured by the ADCP on $02 / 07 / 16$. The greyscale shading is the VBS and shows the position of the zooplankton in the water column as a function of the time. a Shows the green box delimited by $\mathrm{Z}_{\text {WINDOw }}$ and $\mathrm{T}_{\text {WINDOw }}$ and used by the model to detect the migrating layer. Red dots in (b) show the zooplankton layer where $81 \mathrm{~dB}$

example is provided in Fig. 2b, where the three blue patches show dense aggregations of zooplankton with high VBS not belonging to the migrating layer. These points would be selected by the algorithm and affect the velocity computation in the layer.

Because the choice of $V_{\min }$ can be arbitrary, the algorithm was run by changing $V_{\min }$ from $75 \mathrm{~dB}$, which was the lowest observed value, to $V_{\min }=$ $V_{\max }=85 \mathrm{~dB}$, generating 11 different layer detection and fitting results. Two examples are shown in Fig. 3 for $V_{\min }=75 \mathrm{~dB}$ and $V_{\min }=85 \mathrm{~dB}$. Each image can be then inspected manually to remove spurious results and bad fits, when at least one of the following conditions are met: (1) the algorithm selects points within the target area but outside the layer; this occurs when $V_{\text {min }}$ is too low, such as the case in Fig. 3a; (2) the fitted line cuts across the migrating layer rather than following its centroid; this condition is met when

$\leq \mathrm{VBS} \leq 85 \mathrm{~dB}$. Blue shapes delimit isolated zooplankton patches removed from the algorithm. The red patch in (c) highlights the layer identified by the algorithm. $Z_{\mathrm{s} \text {, lower }}, Z_{\mathrm{s}}$, upper, $\mathrm{Z}_{\mathrm{e}}$, lower and $\mathrm{Z}_{\mathrm{e}}$, upper provide the upper and lower position of the layer when the DVM begins and ends. d Shows the resulting slope of the layer and the bulk velocity $v_{\mathrm{up}, 81}$ for $V_{\min }=81 \mathrm{~dB}$

$V_{\min }$ is too low or high. When $V_{\min }=85 \mathrm{~dB}$ (Fig. 3b), too few points, which lack alignment with the centre of the target layer, were picked to correctly estimate the slope.

After excluding the fits that meet the rejection criteria previously defined, the velocity of the accepted fits can be bootstrapped to estimate the mean bulk velocity $v_{\text {up }}$ and its $95 \%$ confidence interval. For example, by choosing $V_{\min }$ from 78 to $83 \mathrm{~dB}$ for the 2 July migration, $v_{\text {up }}=2.57 \pm 0.1 \mathrm{~mm} \mathrm{~s}^{-1}$ (Fig. 3c). This procedure was applied for both 2015 and 2016, producing a time series of sunset migration velocities $v_{\text {up }}$ and sunrise velocities $v_{\text {down }}$ (Fig. 4). The "Electronic Supplementary Material" document reports in detail the results of the layer detection algorithm for each analysed day (Online Resources 1-7). 

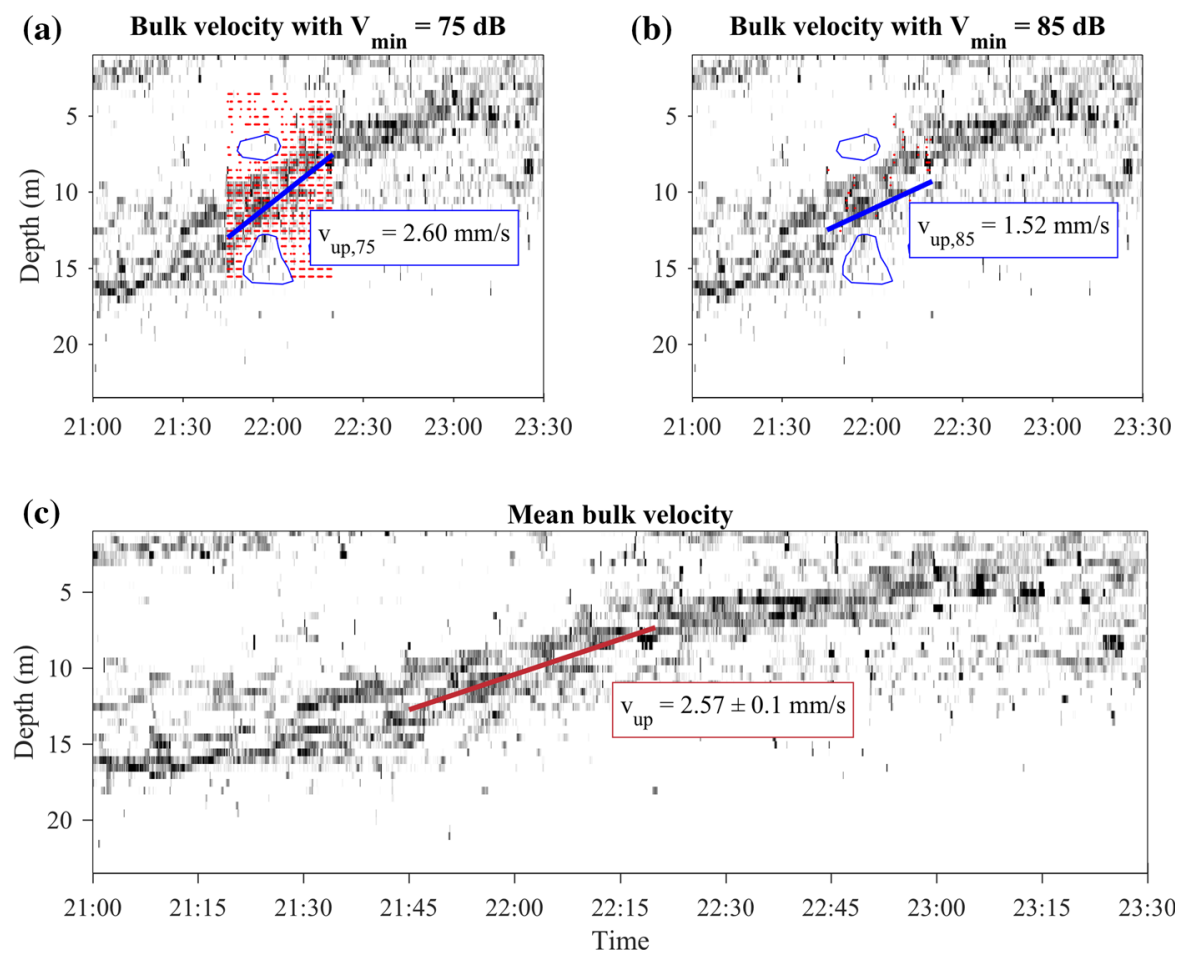

Fig. 3 Algorithm results with two other values of $V_{\min }$. a Shows the case with a low value, where almost all the points in the target area are selected. When $V_{\min }$ is too high as in (b), the resulting slope is off. In both cases, the slope is marked as invalid. c Depicts the final result of $v_{\text {up }}$ via bootstrapping

2015
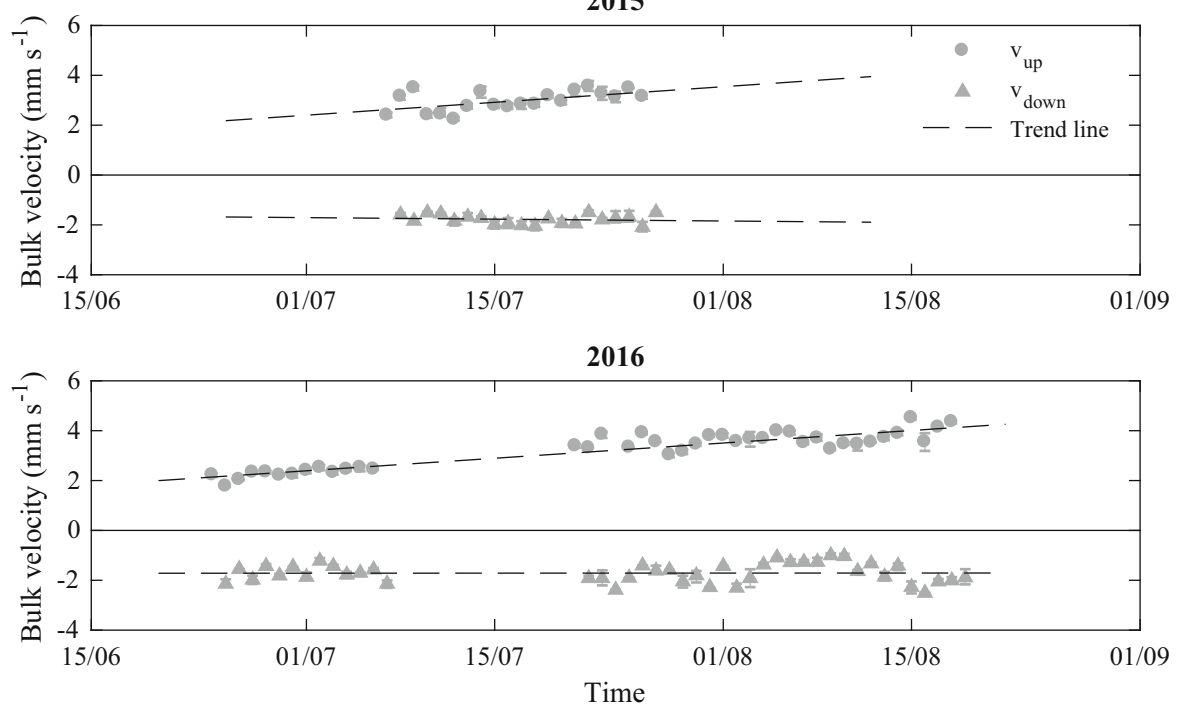

Fig. 4 Time series of bulk velocity $v_{\text {up }}$ at sunset (grey dots, positive values) and $v_{\text {down }}$ at sunrise (grey triangles, negative values) in 2015 and 2016. Error bars show the 95\% confidence interval from the bootstrap method of the valid fittings of $v_{\text {up }}$ and $v_{\text {down }}$. Some error bars are not visible because the interval is too small. The black dashed lines show instead the trend lines fitted to the points 


\section{Temperature measurements}

The vertical temperature stratification was assessed with a thermistor chain deployed in location " $\mathrm{T}$ " (Fig. 1). The chain consisted of 10 RBR thermistors (Solo T, RBR Ltd.) with a temperature accuracy of $\pm 0.002^{\circ} \mathrm{C}$ and 5 Hobo loggers (TidbiT v2, Onset Computer) with an accuracy of $\pm 0.2^{\circ} \mathrm{C}$. Data were sampled every $5 \mathrm{~min}$. Data were available from June to October 2015 and from May until mid-August 2016 (Fig. 5). The mean temperature that the zooplankton experienced during the ascent phase of the DVM can be obtained by overlapping the thermistor chain data with the position and timing of the zooplankton acoustic shape for each migration date (Fig. 6).

\section{Turbulence estimation}

To assess the effect of turbulence on zooplankton swimming velocity, profiles of temperature fluctuations were acquired at location "S" (Fig. 1) with a Self-Contained Autonomous MicroProfiler (SCAMP), a temperature microstructure profiler, following the sampling procedure in Simoncelli et al. (2018). After splitting each profile into 256-point $(25 \mathrm{~cm}) \mathrm{segments}$, turbulence was assessed in terms of turbulent kinetic energy (TKE) dissipation rates $\varepsilon$. Dissipation rates were estimated for each segment using the theoretical spectrum proposed by Batchelor (1959):

$S_{\mathrm{B}}(k)=\sqrt{\frac{q}{2}} \frac{\chi_{T}}{k_{\mathrm{B}} D_{\mathrm{T}}} \alpha\left(e^{-\alpha^{2}} / 2-\alpha \int_{\alpha}^{-\infty} e^{-x^{2} / 2} \mathrm{~d} x\right)$

where $q=3.4$ is a universal constant (Ruddick et al., 2000), $k_{\mathrm{B}}=\left(\varepsilon / v D_{\mathrm{T}}^{2}\right)^{1 / 4}$ the Batchelor wavenumber, $k$ the wavenumber and $\alpha=k k_{\mathrm{B}}^{-1} \sqrt{2 q}$. By fitting the observed spectrum $S_{\mathrm{obs}}$ to $S_{\mathrm{B}}(k)$, it was possible to estimate $k_{\mathrm{B}}$ and then $\varepsilon$. Bad fits, that provided invalid $\varepsilon$, were rejected and removed using the statistical criteria proposed by Ruddick et al. (2000).

On each date, an average of six turbulence profiles were acquired to ensure a statistically reliable estimation of $\varepsilon$. Profiles were then time-averaged to obtain
Fig. 5 Contour plot of temperature in 2015 (panel above) and 2016 (panel below) from the thermistor chain
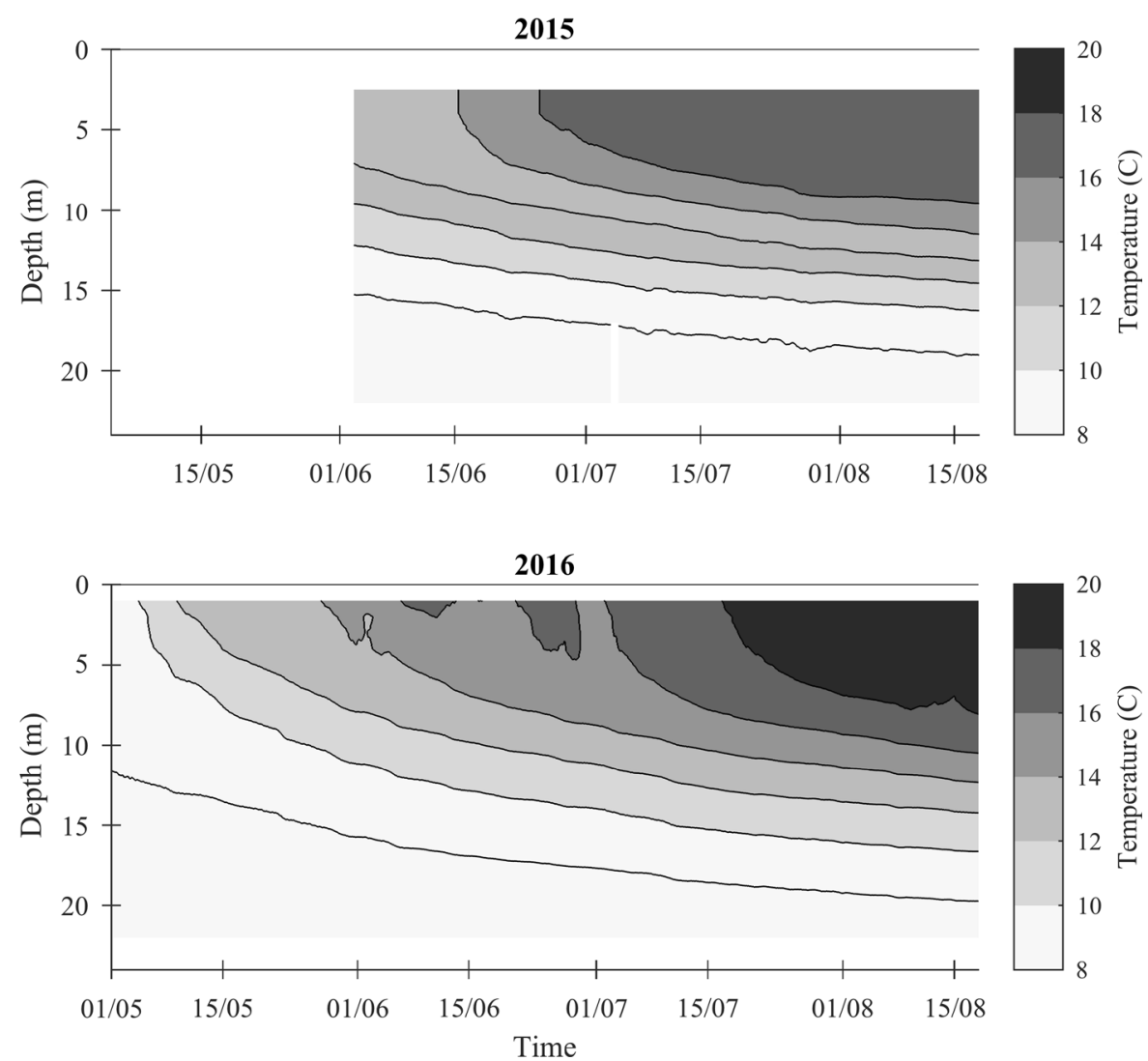

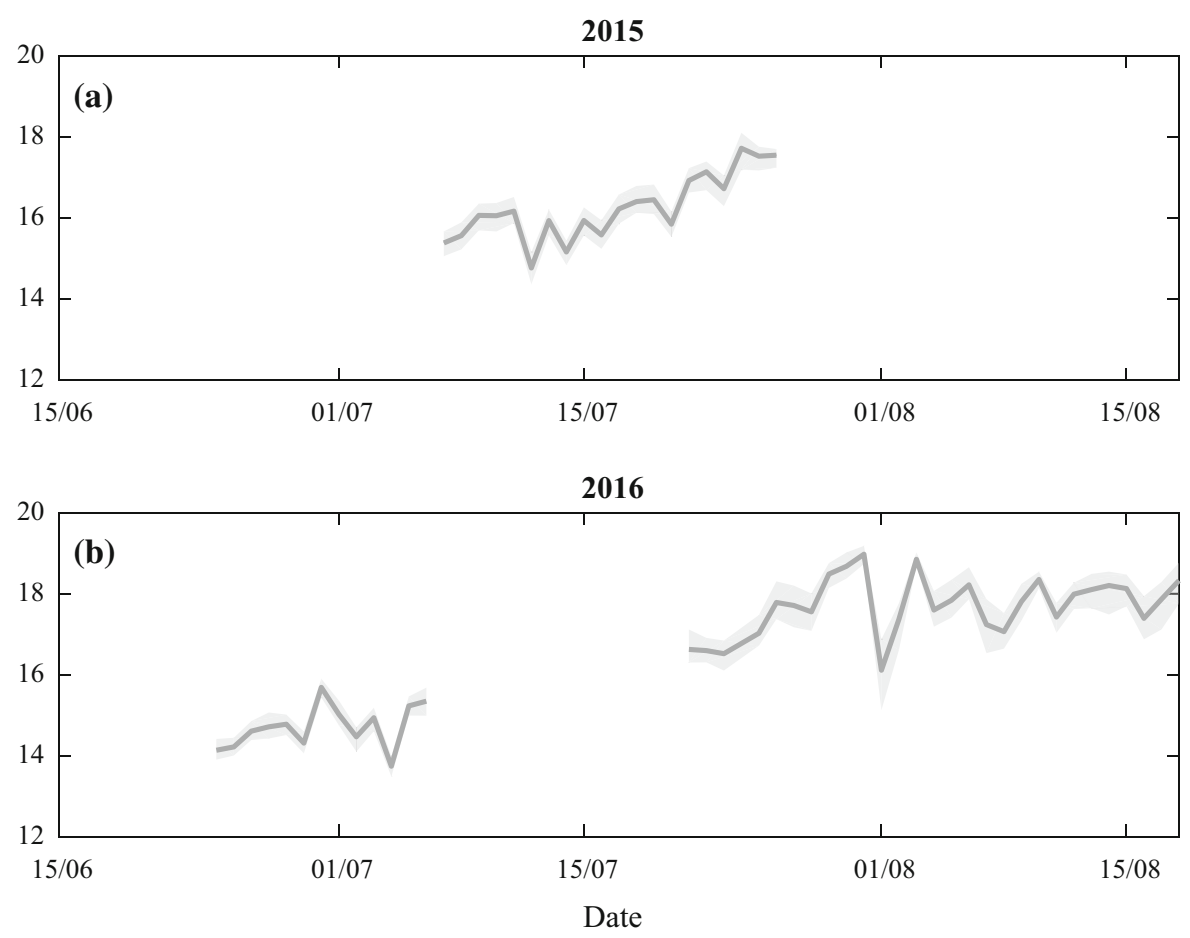

Fig. 6 Mean temperature in the migrating layer (thick line) and its 95\% confidence interval (shaded area)

one profile per sampling date. Profiles from 17 September 2015 and 9 June 2016 were not processed because the SCAMP thermistors provided unreliable data.

The daily-averaged profiles of $\varepsilon$ are reported as "Online Resources 8" in the "Electronic Supplementary Material". Profiles were then depth-averaged throughout the whole water column to obtain the time series of the dissipation rates of TKE (Fig. 7). Data from the profiles were not averaged based on the zooplankton position because turbulence data were not always available on the same days as the acoustic measurements (see black dots vs. green areas in Fig. 7).

\section{Chlorophyll-a concentration}

Chlorophyll- $a$ concentration profiles were acquired at sampling station "S" (Fig. 1). Data were collected from approximately $0.5 \mathrm{~m}$ from the lake surface with a depth resolution of $2 \mathrm{~mm}$ between $5 \mathrm{~h}$ and $5 \mathrm{~min}$ before dusk. Chlorophyll- $a$ was sampled five times in JulyAugust 2015 and ten times between May and August
2016 (see black triangles in Fig. 8). At least five profiles were sampled on each date.

Profiles were acquired using a fluorometer mounted on the SCAMP and manufactured by PME. The sensor excites the water with a blue L.E.D. emitter at $455 \mathrm{~nm}$ in a glass tube to avoid interference with ambient lighting. It then measures the voltage from the light emitted from the chlorophyll with a photo-diode. On each date, voltage profiles were binned every $30 \mathrm{~cm}$ and time-averaged to obtain one profile. Voltage data were finally converted to chlorophyll- $a$ concentration using a linear calibration curve provided in Online Appendix A.

Potential food availability during the DVM was estimated by vertically averaging the chlorophyll$a$ concentration from the available chlorophyll- $a$ profiles (Fig. 9). Since chlorophyll- $a$ concentration was not available for all the dates with the acoustic measurements (green areas in Fig. 9), a linear interpolation was used to estimate missing chlorophyll concentration data between the available observations (red line in Fig. 9). This is the final time series used in subsequent correlations. 
Fig. 7 Time series of time and depth-average TKE dissipation rates $\varepsilon$ (dots) on a logarithmic scale. The green areas show the time period when the acoustic measurements are available
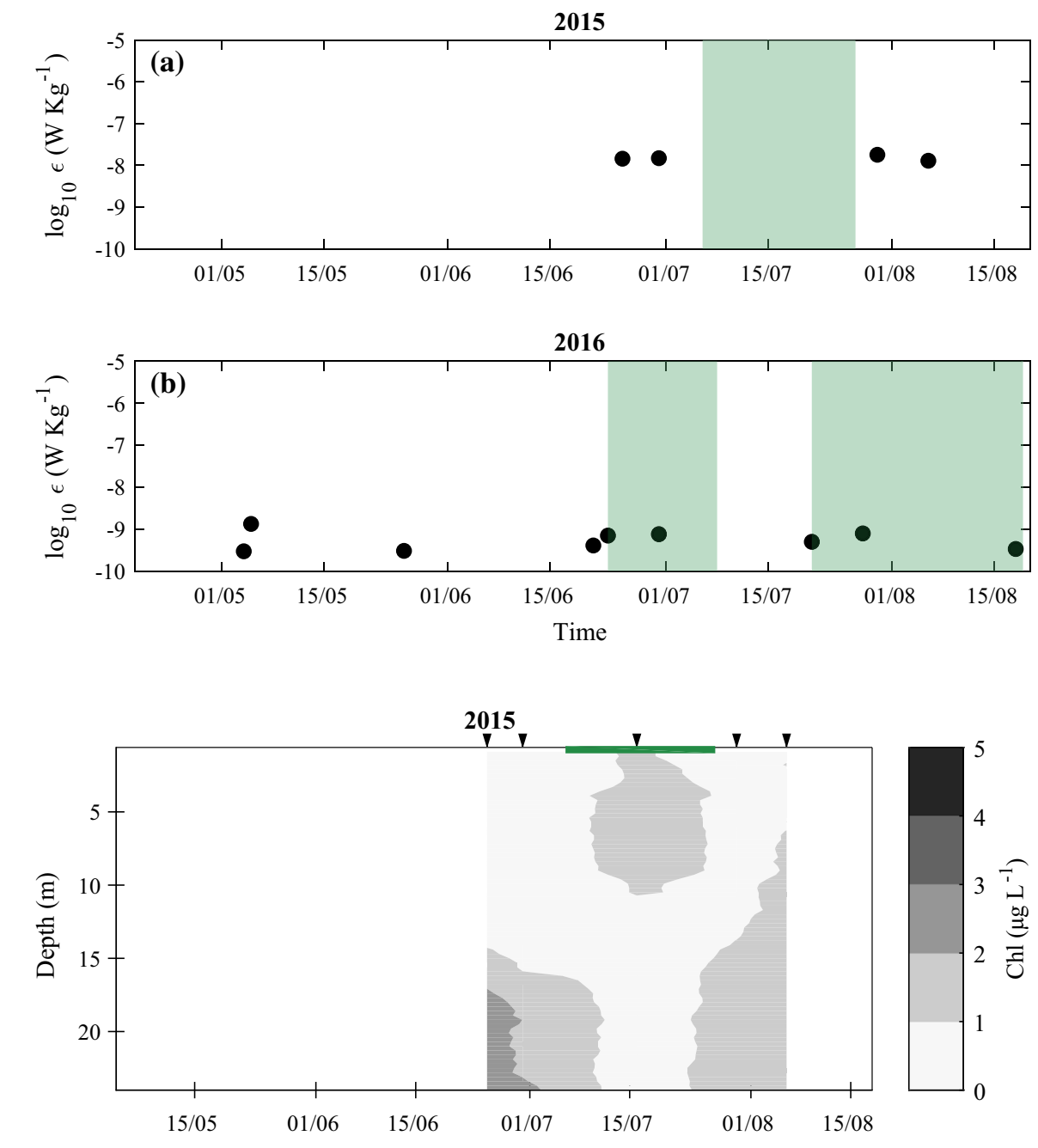

Fig. 8 Contour plot of chlorophyll- $a$ concentration profiles collected in the lake in 2015 and 2016. The colour-bar on the right shows the measured concentration, while the black triangles indicate the time when vertical profiles were collected with the SCAMP fluorometer. The green lines show the periods when the acoustic measurements were taken

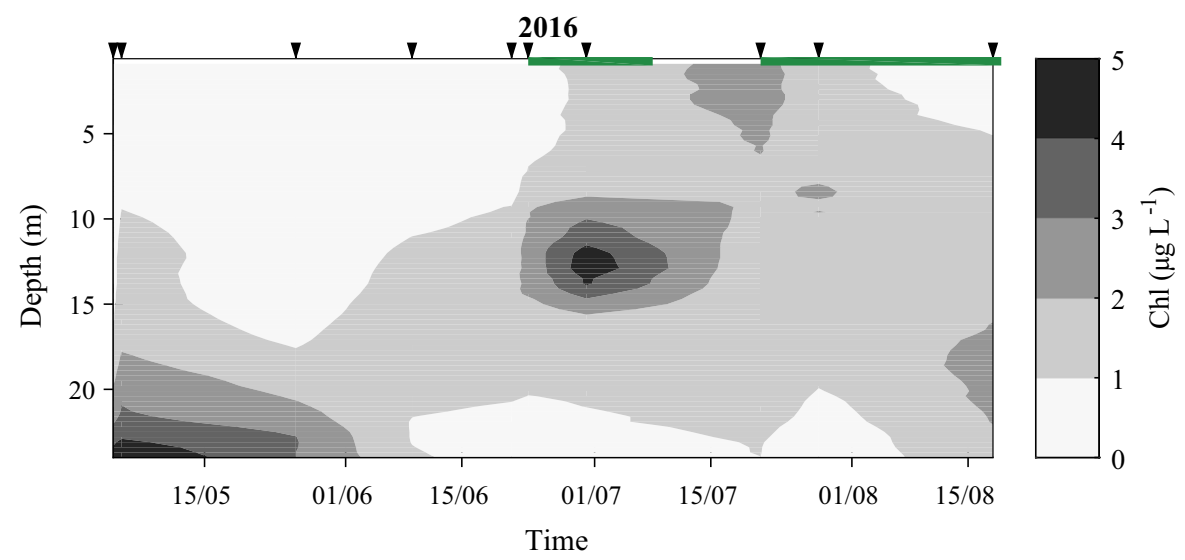


Fig. 9 Time series of watercolumn-averaged concentration of chlorophyll- $a$ in 2015 and 2016. Black dots indicate the day when the chlorophyll- $a$ profiles were averaged. The red line represents the time series employed in the correlation. The green areas show the time period when the acoustic measurements are available
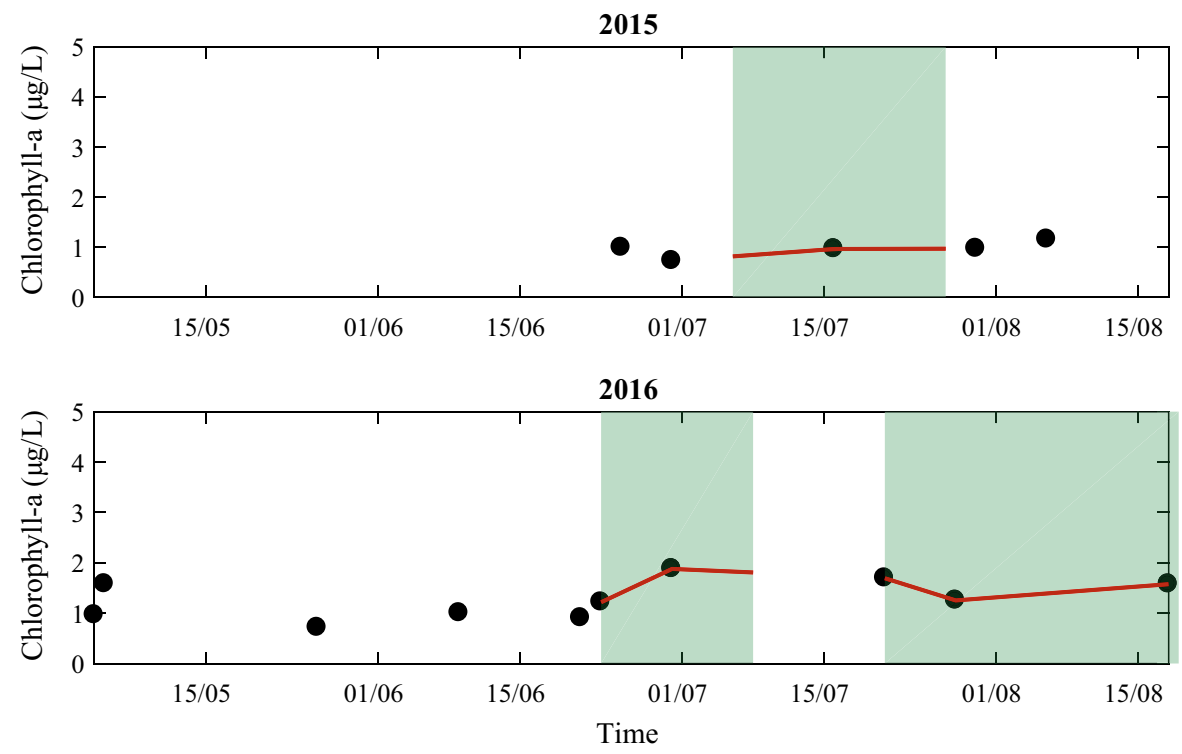

\section{Underwater light conditions}

To characterise the underwater light conditions, surface solar radiation $I_{0}$ was measured with a frequency of 5 minutes by a meteorological station located in Kilmersdon (Radstock, UK), $2 \mathrm{~km}$ from the site. Data were available for the studied period with the exception of 4 July 2016. Photosynthetically active radiation (PAR) profiles $I_{\mathrm{PAR}}$ were also collected at the same time as chlorophyll- $a$ concentration profiles. The PAR was measured with a Li-Cor LT-192SA underwater radiation sensor mounted facing upwards on the SCAMP. On each sampling date, $I_{\mathrm{PAR}}$ profiles were filtered with a moving average filter to remove noise and then binned and time-averaged to obtain a mean PAR profile $\overline{I_{\text {PAR }}}$ (Fig. 10). Profiles collected on 16 July 2016 were discarded because no valid data were recorded. A $20-\mathrm{cm}$ Secchi disc was employed to measure the Secchi depth $z_{\text {SD }}$ in June-July 2015 and April-August 2016 (Fig. 11).

The light extinction coefficient $K$ was then estimated from PAR $\left(K_{\mathrm{PAR}}\right)$ and Secchi disc data $\left(K_{\mathrm{SD}}\right)$. The $\overline{I_{\mathrm{PAR}}}$ profiles were fitted the Lambert-Beer equation to estimate $K_{\mathrm{PAR}}$ (Armengol et al., 2003):

$\overline{I_{\mathrm{PAR}}}=\overline{I_{\mathrm{PAR}, 0}} \cdot e^{-K_{\mathrm{PAR}} \cdot z}$

where $\overline{I_{\mathrm{PAR}, 0}}$ is the surface PAR (Fig. 12, black circles). The ambient attenuation coefficient $K_{\mathrm{SD}}$ was determined from the Secchi disc depth $z_{\mathrm{SD}}$ (Fig. 12, empty triangles) using the following empirical relationship (Armengol et al., 2003):

$K_{\mathrm{SD}}=1.7 / z_{\mathrm{SD}}$

Finally, the underwater light conditions at the depth where the zooplankton started the DVM can be described in terms of relative change in light intensity $S$ (Ringelberg \& Flik, 1994). This quantity can be estimated by using the definition provided by Ringelberg (1999) and assuming that the light intensity $I$ in the water column decayed exponentially with the depth $z$ :

$S=\frac{\mathrm{d} \ln I(t)}{\mathrm{d} t}=\frac{\mathrm{d} \ln I_{0}(t)}{\mathrm{d} t}-\frac{\mathrm{d} K(t)}{\mathrm{d} t} \cdot z$

where $t$ is the time, $I_{0}$ the surface solar radiation and $K$ the light extinction coefficient. If $K$ is time-independent, $S$ is depth-independent and reduced to:

$S=\frac{\mathrm{d} \ln I_{0}(t)}{\mathrm{d} t}$

By employing a linear correlation to the time series of the natural $\log$ of the solar radiation $\left(\ln I_{0}(t)\right)$ during the DVM, a slope can be estimated that provides the mean value of $S$ (Fig. 13).

\section{Zooplankton concentration}

Zooplankton samples were also collected to characterise the zooplankton population density and vertical 

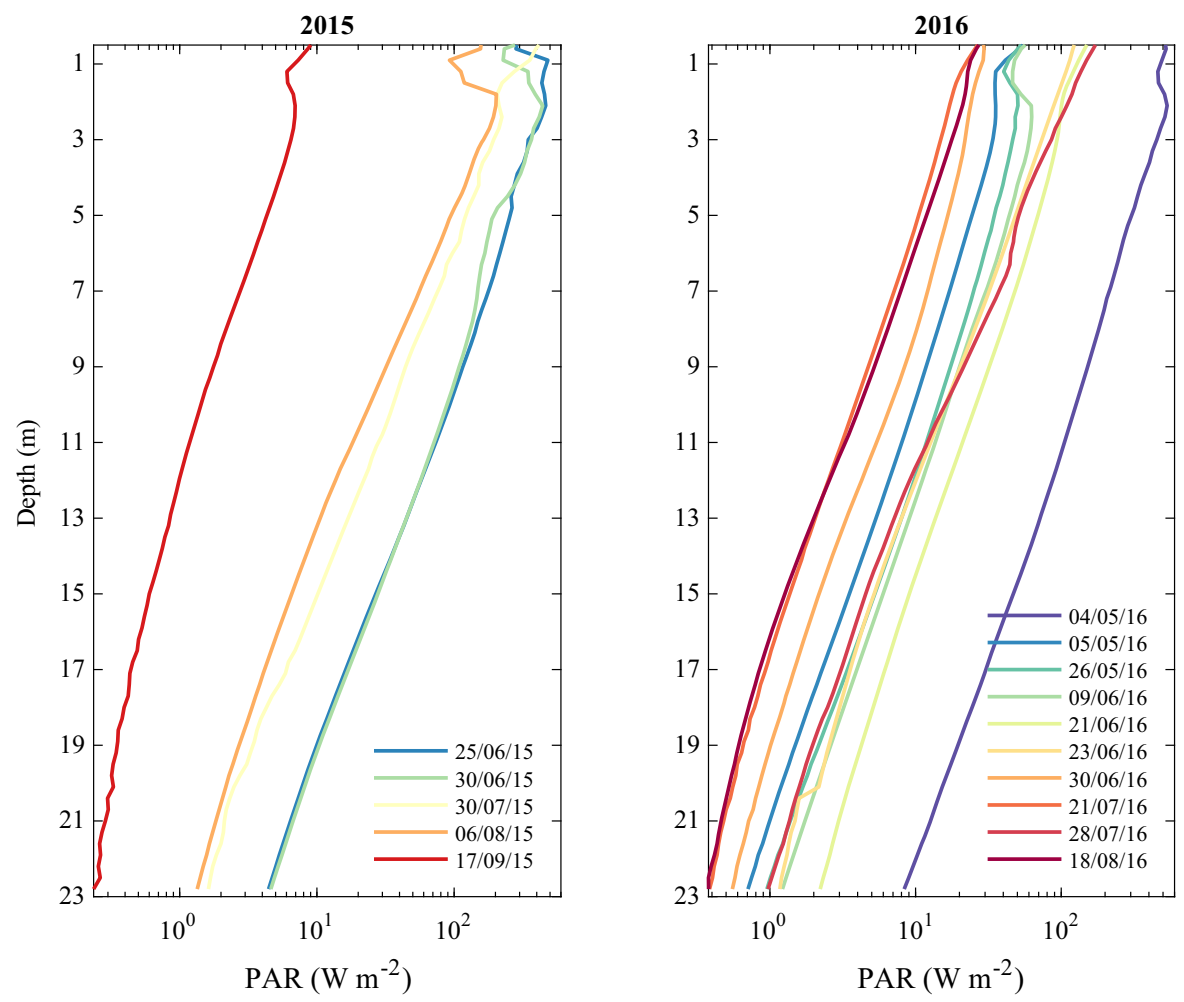

Fig. 10 Photosynthetically active radiation (PAR) profiles in 2015 and 2016 on a logarithmic scale
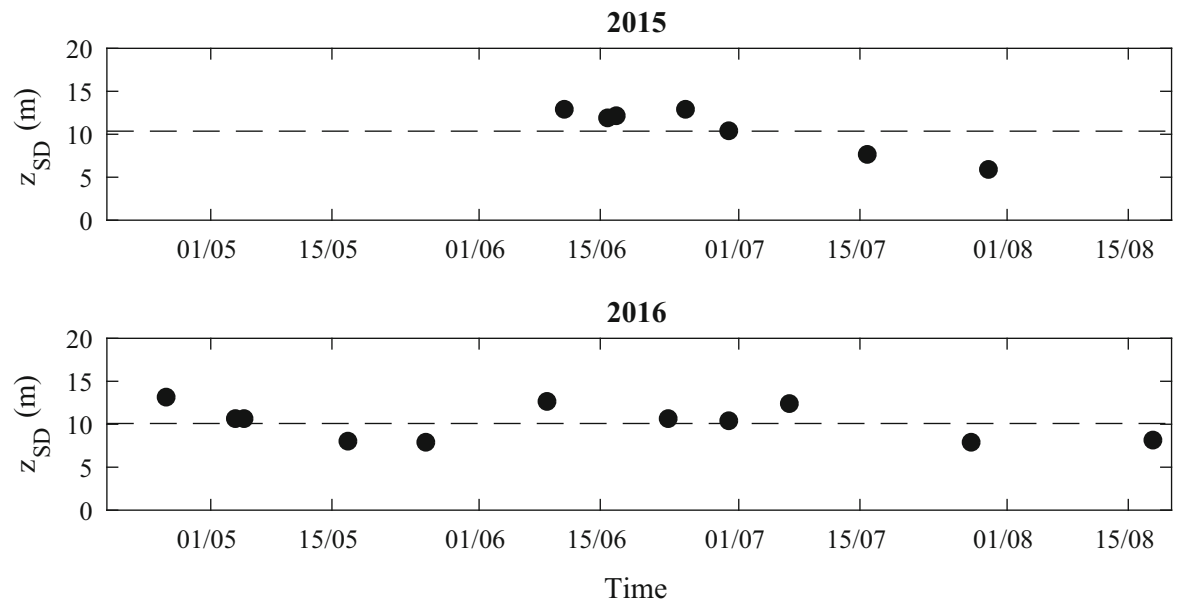

Fig. 11 Time series of Secchi disc depth $z_{\mathrm{SD}}$ in 2015 and 2016. The dashed horizontal line represents the mean depth from the data

distribution. A conical net (Hydro-Bios) mounted on a stainless-steel hoop with a cowl cone (mesh $=100 \mu \mathrm{m}$, diameter $d=100 \mathrm{~mm}$, length approximately $50 \mathrm{~cm}$ ) was used for this purpose. The water column was sampled at location "S" (Fig. 1) before the DVM, by towing the net through consecutive layers of thickness $h=3 \mathrm{~m}$. Three samples $(n=3)$ were collected and pooled for each stratum. Samples were then stored in a $70 \%$ ethanol solution to fix and preserve the organisms and prevent decomposition (Black \& Dodson, 2003). Four tows were acquired in June-July 2015 and 10 tows from 
Fig. 12 Time series of light extinction coefficients from PAR profiles (black circles) and Secchi depths (empty triangles). The green areas show the time period when the acoustic measurements are available

Fig. 13 Time series of mean relative change in light intensity $S$ during the migration
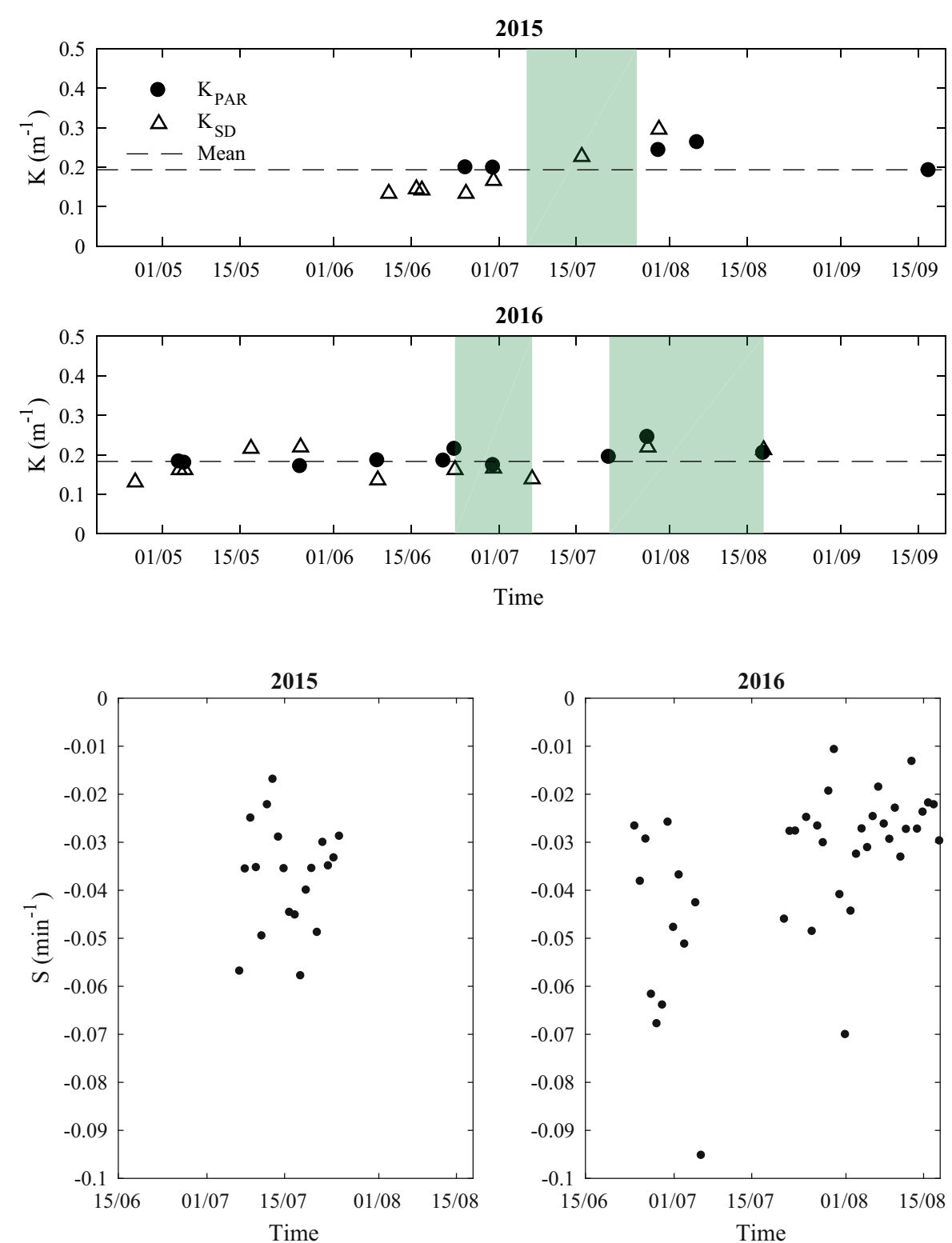

May to August 2016. Zooplankton were enumerated by counting the organisms under a dissecting microscope in three replicate sub-samples of each sample. Four zooplankton groups were distinguished: Daphnia spp., adult and copepodite-stage copepods, small Cladocera and copepod nauplii. The concentration of each group was then estimated by dividing the abundance by the filtered water volume $V=\pi / 4 \cdot d^{2}$. $h / n$ (Fig 14). The complete profiles of zooplankton concentration are reported in the "Electronic Supplementary Material" as "Online Resources 9 and 10".
Net tows do not, however, allow estimation of zooplankton concentration within the migrating layer and during the DVM with adequate time and vertical resolution. The VBS can be used to provide suitably resolved data on zooplankton concentration and size (Sutor et al., 2005; Record \& de Young, 2006; Hembre \& Megard, 2003; Huber et al., 2011; Barth et al., 2014; Inoue et al., 2016) and was available during the DVM. For each migration dates, the VBS was depth-averaged within the zooplankton layer to provide the mean zooplankton concentration during the vertical ascent (Fig. 15). 

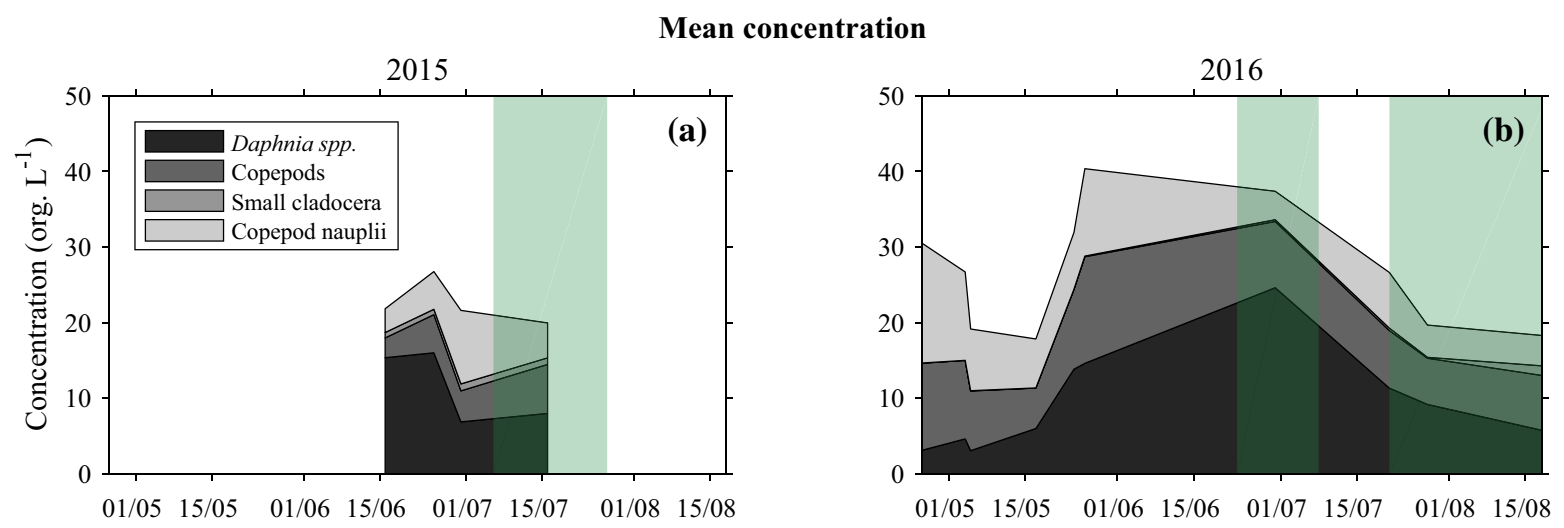

Max concentration

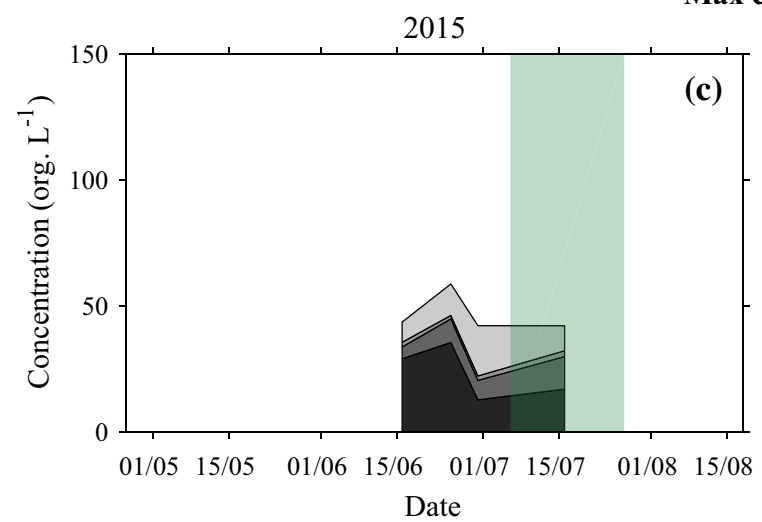

Fig. 14 Stacked plots of mean concentration in the water column (a, b) and maximum concentration $(\mathbf{c}, \mathbf{d})$ of Daphnia spp., adult and copepodite-stage copepods, small Cladocera and

\section{Zooplankton position}

The VBS data can be further used to extract more information about the zooplankton behaviour in relation to the DVM. The acoustic shape (Fig. 2c) from the image-processing algorithm also provides the zooplankton position in the water column prior the DVM and when the migration ends. By taking the average of the upper and lower limits of the shape when the DVM begins $\left(Z_{\mathrm{s}}\right.$, lower and $Z_{\mathrm{s}}$, upper $)$, it is possible to infer the average depth range within which the organisms were found before moving (Fig. 16, black dots). By repeating the same operation when the DVM stops, the two depths $Z_{\mathrm{e}}$, lower and $Z_{\mathrm{e}}$, upper once averaged provide the mean location where the organisms completed the migration and started spreading out near the surface (Fig. 16, empty dots).

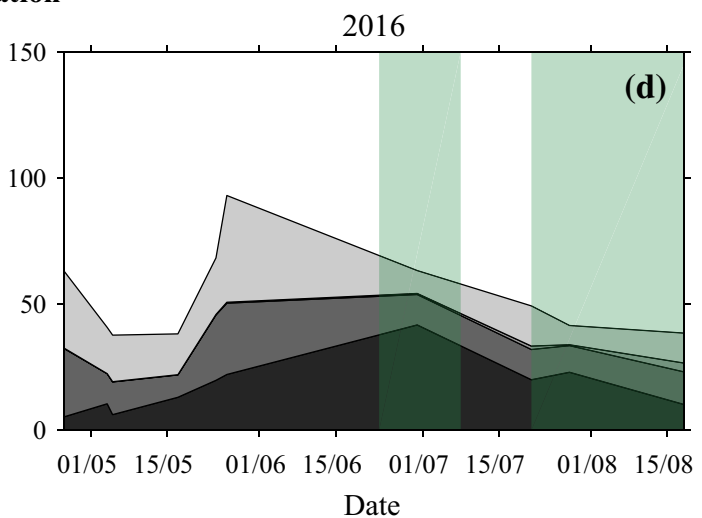

copepod nauplii, from the net tows. The green areas show the time period when the acoustic measurements are available

Modelling of $v_{\text {down }}$

The zooplankton sinking velocity $U_{\text {sink }}$ was modelled with Stokes-like equations and by using organism size and density measured from laboratory experiments. The estimated value of $U_{\text {sink }}$ can then be compared to the downwards velocity $v_{\text {down }}$ to independently verify if zooplankton sank during the descending phase of the DVM. We limited our attention to Daphnia because its hydrodynamics can be easily described by mathematical models, in contrast to other migrating genera. No data exist on the rate of sinking of live copepods. Moreover, they sink frequently with the body orientated in a horizontal or oblique position (Paffenhöfer \& Mazzocchi, 2002) and that angle is not known. Daphnia sink instead mostly vertically (Dodson et al., 1995). 

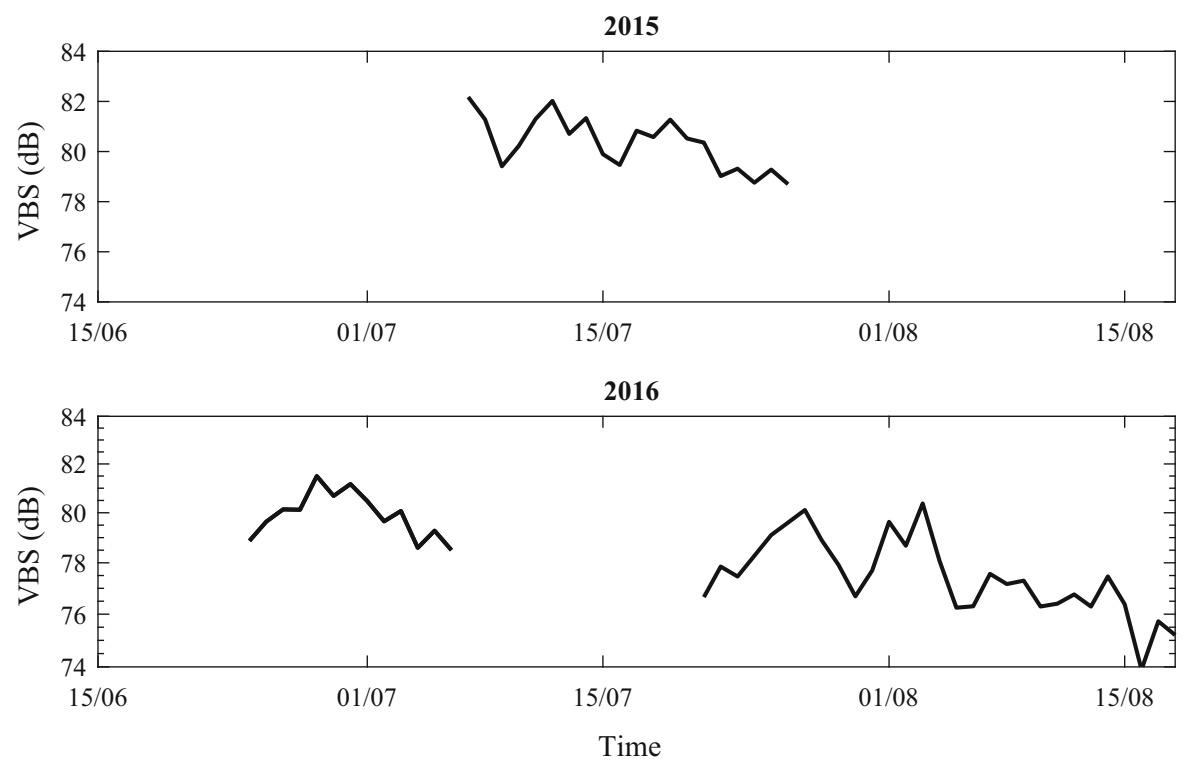

Fig. 15 Mean volume backscatter strength of the migrating layer during the DVM in 2015 and 2016. The 95\% confidence interval was not reported because was too small

2015
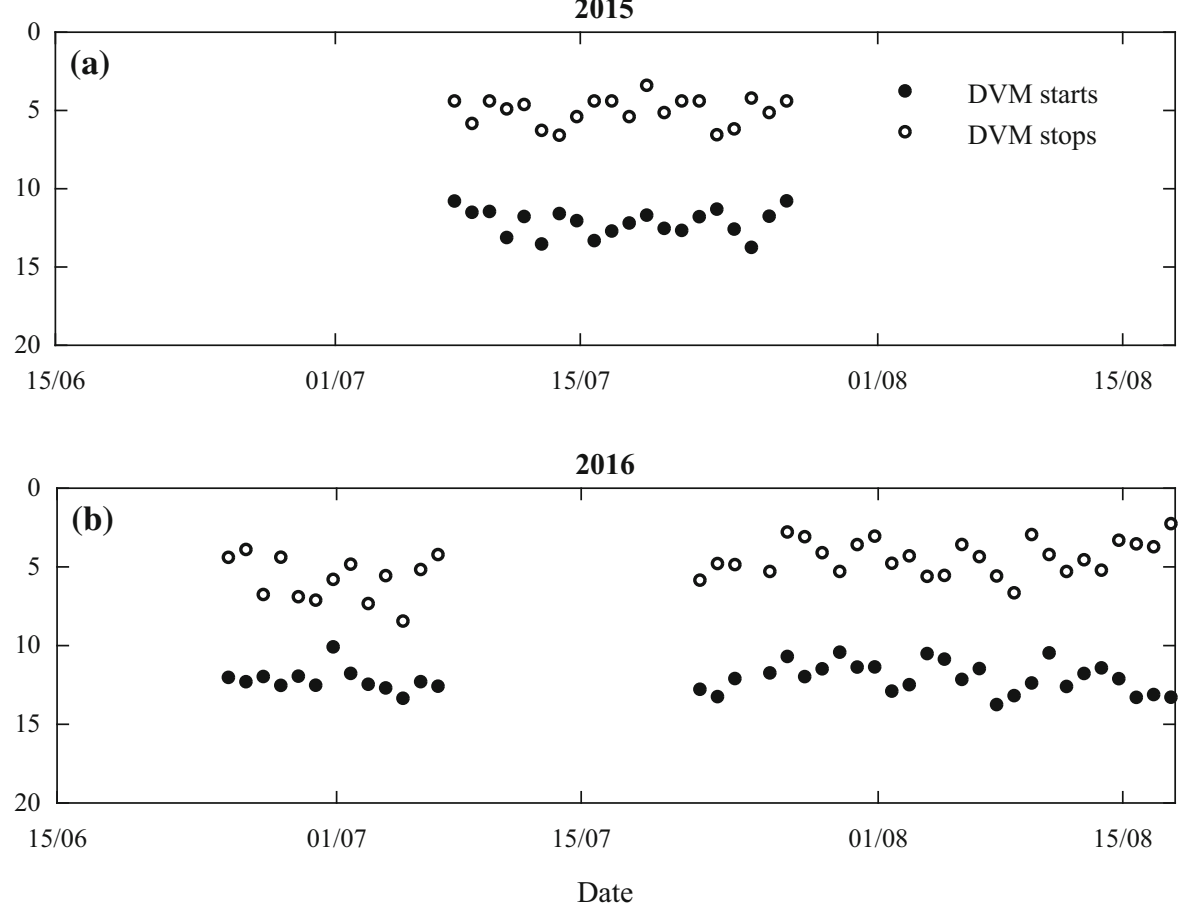

Fig. 16 Mean zooplankton position before the DVM (full dots) and after DVM (empty dots) when they reach the surface in 2015 (a) and 2016 (b) 


\section{Model}

If zooplankton passively descend during the DVM, $U_{\text {sink }}$ depends only on gravity, fluid characteristics and individual size and shape (Ringelberg \& Flik, 1994; Kirillin et al., 2012). Moreover, assuming that zooplankton individuals do not interfere with each other while sinking, $U_{\text {sink }}$ can be approximated by using the average sinking rate of a single organism. The sinking rate $U_{\text {sink,s }}$ of a spherical Daphnia, as a function of the water temperature $T$, can be found by balancing the Stokes drag force exerted by the fluid $\left(F=6 \pi \mu R U_{\mathrm{s}}\right)$ with the body buoyancy $\left(B=\operatorname{Vg}\left(\rho_{\mathrm{d}}-\rho_{\mathrm{w}}\right) / \rho_{\mathrm{w}}\right)$ :

$U_{\text {sink }, \mathrm{s}}(T)=\frac{2}{9} R^{2} g \frac{\rho_{\mathrm{d}}-\rho_{\mathrm{w}}(T)}{\mu(T)}$

where $V$ is the animal volume, $R$ the body radius, $g$ the gravitational acceleration, $\rho_{\mathrm{d}}$ the Daphnia density, and $\rho_{\mathrm{w}}(T)$ and $\mu(T)$ the water density and dynamic viscosity, respectively. However, Daphnia are not spherical and Eq. 7 was thus improved by assuming that Daphnia are an ellipsoid with width $w=2 a_{\mathrm{e}}$ and length $l=2 b_{\mathrm{e}}$ (Fig. 17b). The new body drag is:
$F_{\mathrm{d}, \mathrm{c}}=F \cdot K_{\mathrm{e}} \quad$ with

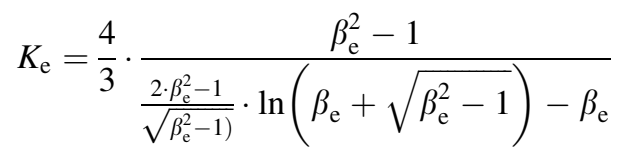

where $\beta_{\mathrm{e}}=b_{\mathrm{e}} / a_{\mathrm{e}}$. The new mean velocity is:

$$
U_{\text {sink }, \mathrm{e}}(T)=\frac{U_{\mathrm{s}}(T)}{\beta_{\mathrm{e}} \cdot K_{\mathrm{e}}}
$$

Accounting for the additional drag from the antenna, the two appendages can be modelled as two cylindrical needles with dimensions $a_{\mathrm{c}}$ and $b_{\mathrm{c}}$ (Fig. 17b). The new equation is:

$$
U_{\text {sink }}(T)=\frac{2}{3} \cdot g \cdot \frac{\rho_{\mathrm{d}}-\rho_{\mathrm{w}}(T)}{\mu(T)} \cdot \frac{2 \cdot a_{\mathrm{c}}^{2} \cdot b_{\mathrm{c}}+a_{\mathrm{e}}^{2} \cdot b_{\mathrm{e}}}{\frac{4 \cdot b_{\mathrm{c}}}{\ln \left(2 \cdot \beta_{\mathrm{c}}\right)}+3 \cdot a_{\mathrm{e}} \cdot K_{\mathrm{e}}}
$$

where and $\beta_{\mathrm{c}}=b_{\mathrm{c}} / a_{\mathrm{c}}$.

\section{Daphnia size}

In order to parametrize the above model, morphometric data on twenty specimens were measured under a Leica M205C dissecting microscope. The measured
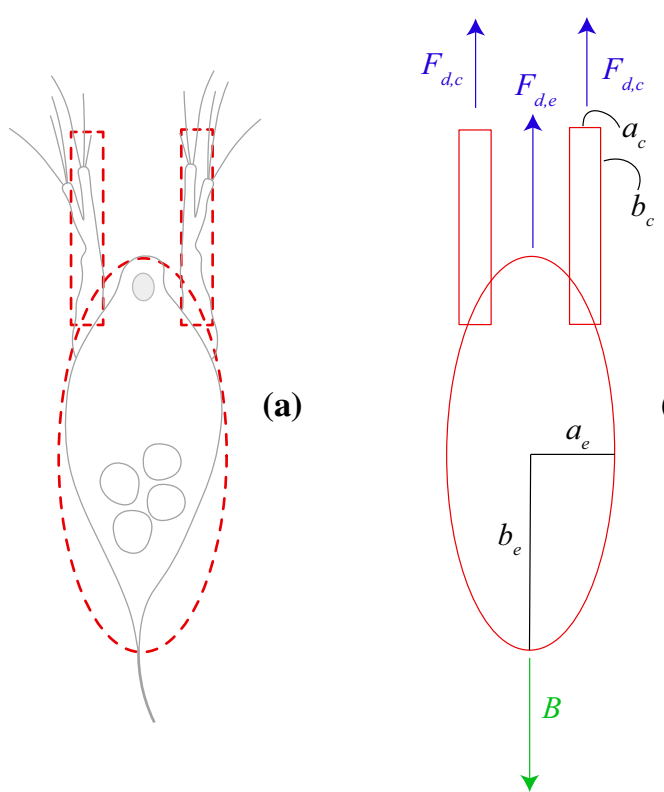

(b)

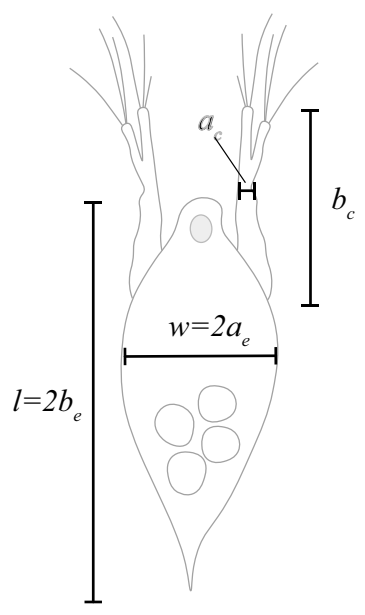

(c)

measured lengths of Daphnia under the microscope. $l$ is the body length, $w$ its width. The length of the second set of antennae is $b_{\mathrm{c}}$ while its width $a_{\mathrm{c}}$
Fig. 17 Daphnia are modelled using an ellipsoid for the body and two cylinders for the antennae (a). The new model (b) balances the buoyancy $B$ with the additional drag $\left(F_{\mathrm{d}, \mathrm{c}}\right.$ and $\left.F_{\mathrm{d}, \mathrm{e}}\right)$ accounting for the body lengths $a_{\mathrm{e}}, b_{\mathrm{e}}, a_{\mathrm{c}}$ and $b_{\mathrm{c}}$. $\mathbf{c}$ Shows the 
lengths (Fig. 17c) are: $b_{\mathrm{e}}$ is half the body length $l$ and $a_{\mathrm{e}}$ half the body width. The arm length is $b_{\mathrm{c}}$ and its width $a_{\mathrm{c}}$.

\section{Daphnia density}

The density of Daphnia carcasses $\rho_{\mathrm{d}}$ was assessed using the density gradient method proposed in Kirillin et al. (2012). Nine different fluid densities were created in different cylinders by mixing freshwater with different volumes of sodium chloride solute $(1 \mathrm{~g}$ $\mathrm{ml}^{-1}$ ). The cylinder densities were verified with a portable densimeter (DMA 35 by Anton Paar) after the water reached the equilibrium with room temperature.

Twenty specimens were then individually tested. Each organism was gently injected and moved from the cylinder with the lowest density $\left(\rho_{\mathrm{w}}=1000 \mathrm{~kg}\right.$ $\mathrm{m}^{-3}$ ) to the one with the highest density $\left(\rho_{\mathrm{w}}=1050\right.$ $\mathrm{kg} \mathrm{m}^{-3}$ ) until the cylinder where the animal reached the neutral buoyancy was found. When the organism stops sinking, it can be assumed that the carcass has a density between the fluid density of the cylinder where it floats and the previous cylinder where it sank. The results are reported in Fig. 18.

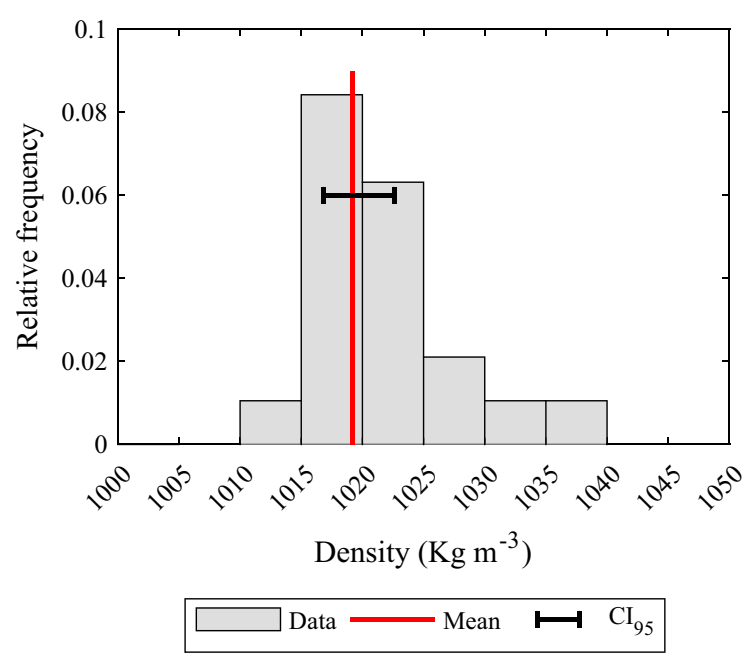

Fig. 18 Frequency distribution of the density of individual Daphnia specimens $(n=20)$. The red line is the sample mean and the horizontal error bar its $95 \%$ confidence interval

\section{Results}

Field observations

Bulk velocity

In 2015 the velocity at sunset ranged from a minimum of $2.23 \mathrm{~mm} \mathrm{~s}^{-1}$ on 12 July to a maximum of $3.55 \mathrm{~mm}$ $\mathrm{s}^{-1}$ on 22 July (Fig. 4, upper panel). In 2016 the time series of $v_{u p}$ showed similar values with a lowest of 2 $\mathrm{mm} \mathrm{s}^{-1}$ at the beginning of June and a maximum of 4.5 $\mathrm{mm} \mathrm{s}^{-1}$ in mid-August (Fig. 4, lower panel). Both time series showed a positive increasing trend over time. In contrast, the bulk velocity at sunrise showed a weak trend over time with a mean of $1.78 \pm 0.08 \mathrm{~mm}$ $\mathrm{s}^{-1}$ in 2015 and $1.71 \pm 0.1 \mathrm{~mm} \mathrm{~s}^{-1}$ in the following year.

\section{Temperature measurements}

The daily average temperature (Fig. 5) showed that the lake was already stratified in June 2015 and the epilimnion started to deepen at the end of the same month. In 2016 the water temperature varied little with depth in early May and stratification began to form in mid-May. During the summer months, the water temperature reached $20^{\circ} \mathrm{C}$.

The mean temperature of the migrating layer during the ascent phase (Fig. 6) showed a seasonally increasing trend in both years. There was also short-term temperature variability due to changing weather conditions. Finally, the $95 \%$ confidence interval (shaded area) is small with an average of $0.34^{\circ} \mathrm{C}$ in 2015 and $0.37^{\circ} \mathrm{C}$ in 2016 . This indicates that temperature variations experienced by zooplankton during the DVM were little.

\section{Dissipation rates of TKE}

The mean dissipation rate in 2015 (Fig. 7a) was $10^{-8}$ $\mathrm{W} \mathrm{kg}^{-1}$, while turbulence was lower in 2016 with an average of $10^{-9} \mathrm{~W} \mathrm{~kg}^{-1}$ (Fig. 7b). The data also show that there is no systematic trend over time in the mean dissipation level in the water column. 


\section{Chlorophyll-a concentration}

The concentration of chlorophyll- $a$ was very low for both years (Fig. 8). In 2015 the concentration in the water column peaked at $2.5 \mu \mathrm{g} \mathrm{l}^{-1}$ near the lake bottom at the end of June. In 2016 the concentration showed a maximum at the beginning of the time series (early May) and it reached a deep maximum of $5 \mu \mathrm{g}$ $1^{-1}$ in July below $10 \mathrm{~m}$. The time series of depthaveraged chlorophyll- $a$ concentration (Fig. 9) showed little evidence of a temporal trend throughout the study period.

\section{Underwater light conditions}

PAR profiles (Fig. 10) showed a linear trend on a semi-logarithmic scale, with the exception of the data above $1 \mathrm{~m}$, indicating an exponential decay with depth of the ambient light in the water column. Some profiles provided $\overline{I_{\mathrm{PAR}}}<50 \mathrm{~W} \mathrm{~m}^{-2}$ because they were collected near dusk. The Secchi disc depths (Fig. 11) showed a mean depth of $10.4 \pm 2 \mathrm{~m}$ in 2015 with a decreasing trend after the beginning of July despite a constant and low chlorophyll concentration in the water column (Fig. 8). In $2016 z_{\text {SD }}$ was on average $10.1 \pm 1 \mathrm{~m}$ and never fell below $8 \mathrm{~m}$.

The time series of $K_{\mathrm{PAR}}$ and $K_{\mathrm{SD}}$ showed a good agreement (Fig. 12). The coefficient $K$ showed a positive trend in 2015, with a mean value of $0.19 \pm$ $0.03 \mathrm{~m}^{-1}$, and stationary conditions in 2016 with a mean of $0.18 \pm 0.01 \mathrm{~m}^{-1}$. It never exceeded $0.22 \mathrm{~m}^{-1}$, with the exception of $K_{\mathrm{SD}}$ at the end of July.

Since $K_{\mathrm{PAR}}$ and $K_{\mathrm{SD}}$ were time-independent, the relative change in light intensity $S$ has been estimated from Eq. 6. The result (Fig. 13) shows that $S$ was always negative and in most of the cases was within the range $S=[-0.1,-0.04] \mathrm{min}^{-1}$, suggested for inducing phototactic behaviour in Daphnia (Ringelberg, 2010).

\section{Zooplankton concentration}

The time series of the zooplankton vertical concentration in 2015 (Fig. 14a) showed that Daphnia was dominant, accounting for up to $80 \%$ of the mean concentration in the water column in June. The concentration remained almost constant until the end of the same month and then it started decreasing reaching a minimum of 7 org. $1^{-1}$ in July. The concentration of adult, copepodite and naupliar stages of copepods was very small in June $\left(\sim 5 \mathrm{org} . \mathrm{l}^{-1}\right)$, but in mid-July they became as abundant as Daphnia with an average density of up 10 org $1^{-1}$. The maximum concentration of zooplankton (Fig. 14c) followed the same trend with a peak of $35 \mathrm{org} .1^{-1}$ of Daphnia at the end of June and a maximum of $20 \mathrm{org} . \mathrm{1}^{-1}$ of copepods (including nauplii).

Data in 2016 displayed a more complete picture of the zooplankton density dynamics. From late April until June, copepods dominated with an average concentration of 27 org. $1^{-1}$ (Fig. 14b). The Daphnia population increased throughout May peaking at 25 org. $1^{-1}$ in July. The density of small cladocera remained very low and negligible with respect to the other species. For the remainder of the summer the total zooplankton abundance decreased, until the end of August where a maximum of 5 org. $1^{-1}$ of Daphnia and 11 org. $1^{-1}$ of copepods were observed. The maximum abundance in 2016 (Fig. 14d) was very similar in magnitude to that observed in 2015 with the exception of copepod nauplii whose abundance reached 42 org. $1^{-1}$ in late May. The concentration declined quickly with a minimum of $12 \mathrm{org} .1^{-1}$ at the end of the time series.

The trend in the VBS of the migrating layer at the time of the migration in 2016 (Fig. 15) is similar to that observed in the time series of the zooplankton concentration from net tows (Fig. 14c, d): VBS peaks at $81.5 \mathrm{~dB}$ at the beginning of July and at $80 \mathrm{~dB}$ at the end of the same month. In 2015 the observations period of the VBS is too short to be compared with the zooplankton concentration. Local variations in VBS can also be observed which were driven by daily variations of zooplankton concentration and thickness of the migrating layer.

\section{Zooplankton position}

Prior to migration, zooplankton (Fig. 16) were found at an average depth of $12.2 \mathrm{~m}$ in both years with a $95 \%$ confidence interval $\mathrm{CI}_{95}=[11.8,12.6] \mathrm{m}$ in 2015 and $\mathrm{CI}_{95}=[11.9,12.4] \mathrm{m}$ in 2016. The depth where they stopped migrating was $5 \mathrm{~m}$ with $\mathrm{CI}_{95}=[4.7,5.5] \mathrm{m}$ in 2015 and $\mathrm{CI}_{95}=[4.5,5.3] \mathrm{m}$ in 2016. 
Correlation between $v_{\text {up }}$ and potential drivers

To investigate potential drivers of the observed variability in $v_{\text {up }}$, the upward bulk velocity was linearly correlated with the temperature (Fig. 6), chlorophyll- $a$ concentration (Fig. 9), the light conditions during the DVM (Fig. 13) and the VBS as a proxy for the in situ concentration and size (Fig. 15). The dissipation rates $\varepsilon$ (Fig. 7) were not used in the correlation, as turbulence values could not be interpolated because of their patchy and unsteady nature. Prior to further analysis, we removed one sampling date due to the absence of data on $S$ in 2016.

The predictors to be included in the multiple linear regression model were tested to assess any possible multicollinearity. The correlation matrix of the variables (Table 1) shows that the VBS was negatively correlated with the temperature $T\left(R_{\mathrm{VBS}, \mathrm{T}}=-0.645\right)$ and weakly related to the chlorophyll- $a$ concentration $\left(R_{\mathrm{VBS}, \mathrm{Chl}}=-0.375\right)$. Chlorophyll concentration was also correlated with the light availability with $R_{\mathrm{S}, \mathrm{Chl}}=0.649$. However, the variance inflation factor (VIF) index for each of the predictors (Table 2) shows that the collinearity among the three variables was weak and unimportant $\left(V I F_{\mathrm{VBS}}=2.532, V B S_{\mathrm{Chl}}=\right.$ 2.123 and $\left.V I F_{\mathrm{S}}=2.123<5\right)$. Variations in the chlorophyll- $a$ concentration were in reality very small, and any small interdependence was likely a numeric artefact.

A model fitting dataset was created from the data by extracting 46 random observations (about $80 \%$ of the original sample). The remaining 12 observations constituted the validation dataset that was later used to validate the prediction of the fitted model. A multiple linear regression was applied to the 46 observations with a significance level $\alpha=0.01$. The model results indicated that there was no significant statistical correlation between $v_{\text {up }}$ and the relative

Table 1 Correlation matrix for the volume backscatter strength $(V B S)$, temperature $(T)$, chlorophyll concentration $(C h l)$ and relative change in light intensity $(S)$

\begin{tabular}{lllll}
\hline & VBS & T & Chl & $S$ \\
\hline VBS & 1 & & & \\
T & -0.645 & 1 & & \\
Chl & -0.376 & -0.076 & 1 & \\
$S$ & -0.088 & -0.364 & 0.649 & 1 \\
\hline
\end{tabular}

change in light intensity $S$ ( $F$ statistic $=-0.927, p$ value $=0.358)$, the food availability (chlorophyll- $a$ ) concentration $(F=-0.2420, P=0.810)$, and $V B S$ $(F=-2.0328, P=0.0482)$. The upward velocity was, instead, significantly correlated with changes in temperature $T\left(F=4.933\right.$ and $\left.P=1.26 \times 10^{-5}\right)$. The linear regression model was further simplified by excluding the other predictors, and the result is reported in Fig. 19a with $P=2 \times 10^{-12}$ and a coefficient of determination $R^{2}=0.66$. The final regression model also predicted the observations from the validation dataset reasonably well (Fig. 19b) with $P=$ $1 \times 10^{-4}$ and $R^{2}=0.79$.

Modelling of $v_{\text {down }}$

The parameters employed in Eqs. 7-10 are reported in Fig. 18 and Table 3 for the Daphnia density $\rho_{\mathrm{d}}$ and sizes, respectively. The mean density of a single Daphnia was $1019.2 \mathrm{~kg} \mathrm{~m}^{-3}$ (red line) with $\mathrm{CI}_{95}=$ $[1016.8,1022.5] \mathrm{kg} \mathrm{m}^{-3}$ (black error bar). The organism's mean body length $l$ was $0.886 \mathrm{~mm}$, while its width $w$ was $0.378 \mathrm{~mm}$, with $\beta_{\mathrm{e}}=2.34$, clearly indicating a deviation from the spheric shape. The antenna length $b_{\mathrm{c}}$ was $0.425 \mathrm{~mm}$ and its width $a_{\mathrm{c}}=$ $0.039 \mathrm{~mm}$. The dependence of the Daphnia sinking rate on the water temperature $T$ changes according to the equation used to model the organism body shape (see Fig. 20). The model for $U_{\text {sink,s }}$ consistently provides larger sinking rates with respect to the other two models with large variations as the water temperature $T$ increases. The difference between $U_{\text {sink,e }}$ and $U_{\text {sink }}$ is about $0.5 \mathrm{~mm} \mathrm{~s}^{-1}$, however, $U_{\text {sink,e }}$ slightly diverges from $U_{\text {sink }}$ for warmer temperatures.

\section{Discussion}

We used for the first time acoustic measurements to quantify the time series of zooplankton displacement velocity during the DVM in an oligotrophic lake. Based upon environmental measurements, and independent physical calculations and modelling, we

Table 2 Variance inflation factor (VIF) for the predictors

\begin{tabular}{llll}
\hline VIF $_{\text {VBS }}$ & VIF $_{\mathrm{T}}$ & $\mathrm{VIF}_{\text {Chl }}$ & $\mathrm{VIF}_{\mathrm{S}}$ \\
\hline 2.532 & 2.513 & 2.135 & 2.123 \\
\hline
\end{tabular}




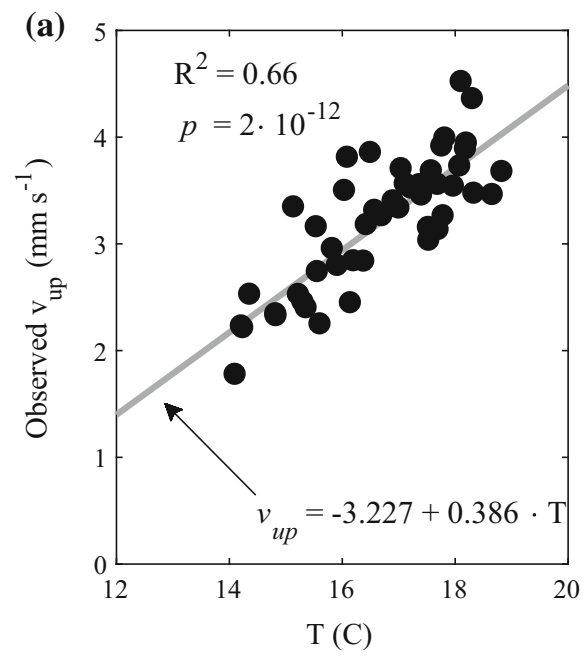

Fig. 19 a Shows the correlation between $T$ and the observed upward velocity. The grey line represents the fitted model to the regression dataset whose equation is reported in the bottom right corner. The upper left corner displays the coefficient of (b)

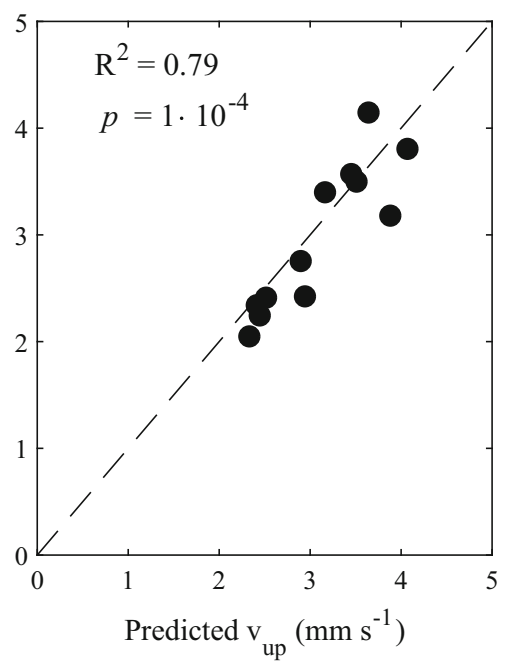

determination $R^{2}$ and the $P$ value of the regression. b Shows the relation between the observed $v_{\text {up }}$ from the validation dataset and the prediction from the regression model (dots). The dashed line is the $1: 1$ relationship
Table 3 Body sizes (see Fig. 17c) measured for Daphnia
The last two rows report the mean and the $95 \%$ confidence interval $\mathrm{CI}_{95}$ via bootstrapping

\begin{tabular}{|c|c|c|c|c|}
\hline Specimen \# & $b_{\mathrm{e}}(\mathrm{mm})$ & $a_{\mathrm{e}}(\mathrm{mm})$ & $b_{\mathrm{c}}(\mathrm{mm})$ & $a_{\mathrm{c}}(\mathrm{mm})$ \\
\hline 1 & 0.406 & 0.217 & 0.624 & 0.029 \\
\hline 2 & 0.421 & 0.218 & 0.492 & 0.050 \\
\hline 3 & 0.415 & 0.221 & 0.404 & 0.044 \\
\hline 4 & 0.326 & 0.129 & 0.226 & 0.028 \\
\hline 5 & 0.479 & 0.153 & 0.422 & 0.038 \\
\hline 6 & 0.448 & 0.230 & 0.439 & 0.028 \\
\hline 7 & 0.477 & 0.203 & 0.473 & 0.051 \\
\hline 8 & 0.518 & 0.170 & 0.342 & 0.044 \\
\hline 9 & 0.490 & 0.151 & 0.381 & 0.034 \\
\hline 10 & 0.422 & 0.234 & 0.360 & 0.052 \\
\hline 11 & 0.342 & 0.116 & 0.425 & 0.033 \\
\hline 12 & 0.499 & 0.207 & 0.421 & 0.034 \\
\hline 13 & 0.518 & 0.170 & 0.342 & 0.044 \\
\hline 14 & 0.490 & 0.151 & 0.381 & 0.034 \\
\hline 15 & 0.422 & 0.234 & 0.360 & 0.052 \\
\hline 16 & 0.342 & 0.116 & 0.425 & 0.033 \\
\hline 17 & 0.499 & 0.207 & 0.421 & 0.034 \\
\hline 18 & 0.491 & 0.172 & 0.573 & 0.046 \\
\hline 19 & 0.462 & 0.202 & 0.606 & 0.045 \\
\hline 20 & 0.384 & 0.265 & 0.384 & 0.027 \\
\hline Mean & 0.443 & 0.189 & 0.425 & 0.039 \\
\hline $\mathrm{CI}_{95}$ & $0.419,0.476$ & $0.164,0.201$ & $0.390,0.466$ & $0.035,0.043$ \\
\hline
\end{tabular}




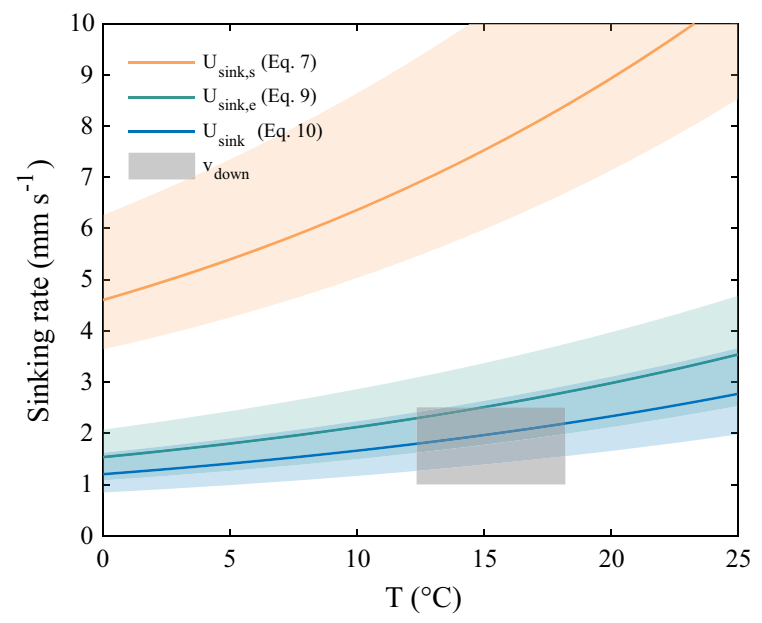

Fig. 20 Average sinking rates of Daphnia as a function of the temperature $\mathrm{T}$. Orange line shows the mean velocity with the organism modelled as a spherical body (Eq. 7) with $R=b_{\mathrm{E}}=$ $0.433 \mathrm{~mm}$ and $\rho_{\mathrm{d}}=1019.2 \mathrm{~kg} \mathrm{~m}^{-3}$; the green line as an ellipse (Eq. 9) with size $a_{\mathrm{e}}$ and $b_{\mathrm{e}}$ without antennae; and the blue line with the new model (Eq. 10) with the mean values of $a_{\mathrm{c}}=0.425$ $\mathrm{mm}$ and $b_{\mathrm{c}}=0.039 \mathrm{~mm}$. The shaded areas show the $95 \%$ confidence intervals calculated using the interval limits CI 95 for $a_{\mathrm{e}}, b_{\mathrm{e}}, a_{\mathrm{c}}, b_{\mathrm{c}}$ and $\rho_{\mathrm{d}}$ in Table 3 . The grey box represents the observed range of the downwards velocity $\left(v_{\text {down }}\right)$ in the field

aimed to infer the environmental drivers that might influence the rate of zooplankton migration in the field.

\section{Upward bulk velocity}

In our correlation model, we hypothesised that $v_{\text {up }}$ may depend on temperature, zooplankton density, food availability and light intensity. Because of lack of sufficient data, fish abundance and turbulence were not included in the correlation analysis. The effect of temperature on zooplankton swimming velocity has been demonstrated by laboratory studies of single swimming organisms (Ringelberg, 2010). When temperature increases, zooplankton metabolic activity rates change (Heinle, 1969; Gorski \& Dodson, 1996; Beveridge et al., 2010), and they can also swim faster because of the reduced drag exerted on their swimming appendages (Larsen \& Riisgård, 2009). Temperature may also enhance phototactic response in Daphnia (Van Gool \& Ringelberg, 2003); however, this was not observed in our results. A stepwise linear regression, with pairwise interactions of all DVM drivers, showed that the interactive effect of $S$ and $T$ on DV was not significant $(F=1.0672, P=0.307)$.

In principle, if zooplankton are present at very high population densities while migrating, organisms would have to reduce the velocity they can swim at to avoid encounters with other animals (i.e., the surrounding space for moving would be limited). The instantaneous speed and the resulting bulk velocity would be smaller. In the opposite scenario, with a low abundance within the migrating layer, organisms would be free to swim unobstructed, reaching the maximum thrust they can propel at, resulting in a higher bulk velocity. Our dataset showed, however, that the VBS was weakly correlated with $v_{\text {up }}$ probably because the zooplankton concentration was not high enough to yield such swimming behaviour. This effect might have been appreciable if measurements had been available also during the peak in zooplankton abundance in June (Fig. 14c, d). The lack of other studies in the literature precludes us from corroborating this hypothesis.

Food availability can both positively and negatively affect Daphnia migration velocity depending on environmental conditions and genetic differences (Dodson et al., 1997a). Our analysis, however, did not provide evidence of this effect because of the stationary chlorophyll- $a$ concentration during the period over which the migration velocities changed.

Surprisingly, the bulk velocity was not affected by the average change in light intensity. Changes in light intensity have been shown to influence zooplankton displacement velocity at the scale of a single DVM (Ringelberg et al., 1991; Ringelberg \& Flik, 1994). However, this relationship was not observed at a multiple-DVM scale, in our study. It is likely that this is due to among-study differences in field conditions, and in the impact of additional drivers and mediators of migratory behaviour.

The lack of data on fish abundance and kairomone concentrations did not allow direct inclusion of predation pressure in our analyses. However, some speculation can be made about its possible effect. While we observed an increasing near-linear temporal trend in $v_{\text {up }}$, predation often has a seasonal peak coinciding with the time at which larval fish hatch and begin actively feeding upon zooplankton; this leads to a stronger zooplankton response to light within that specific period (Van Gool \& Ringelberg, 2003). The 
zooplankton layer depth prior the DVM (black dots in Fig. 16) suggests that the organisms did not change their daytime vertical position during the observation period and that they resided on average at the same depth in both years. If a strong predation pressure had occurred over a specific time period, a repositioning of the population towards deeper layers in the daytime would have been expected during this period (Dodson, 1990; Leach et al., 2014). However, the near-constant migration amplitude suggests that visual predation pressure was present and consistent throughout the whole study period, and thus a sudden increase in that pressure appears unlikely.

Turbulence was not included in our model either. Available measurements could not be interpolated to fill the gaps of missing observations. However, $\varepsilon$ was constant and very low (Fig. 7), approaching the background dissipation level. The lack of a clear temporal trend in turbulence suggest that this could not be an important driver of the observed trend in zooplankton migration velocity.

The correlation model showed that temperature was a primary factor in controlling migration speed in the field with respect to the other DVM drivers. Because zooplankton swim in a low Reynolds number environment, temperature-dependent viscosity is a crucial mediator of their motility. Assuming that the viscosity mainly controls the organism swimming response (Larsen \& Riisgård, 2009), our dataset showed that a viscosity variation of $13 \%$ (from $v=1.8 \times 10^{-6} \mathrm{~m}^{2}$ $\mathrm{s}^{-1}$ at the start of the dataset to $v=1.1 \times 10^{-6} \mathrm{~m}^{2} \mathrm{~s}^{-1}$ in August) led to an increase in velocity of about $61 \%$. The same variation was observed by Larsen et al. (2008) in the laboratory, but over a wider viscosity range (about 36\%) for the instantaneous velocity of the copepod Acartia tonsa Dana, 1849. Moison et al. (2012) found instead an increase of $29 \%$ in the speed of Temora longicornis Müller O.F., 1785 for a viscosity variation of $15 \%$. Because we were dealing with a mean velocity during the migration and no further studies were available, it was not possible to make any direct comparisons with other experiments.

Downwards bulk velocity

The velocity $U_{\text {sink }}$ (blue line in Fig. 20) from our new model matched the observed range of $v_{\text {down }}$ in the field (grey box) within the $95 \%$ confidence interval (blue shaded area). Our analysis also indicates that spherical models are not suitable for reproducing Daphnia sinking rates; $U_{\text {sink,s }}$ (orange line) consistently provided velocities above the falling rates reported in the literature for narcotised animals (Hutchinson, 1967; Gorski \& Dodson, 1996; Ringelberg \& Flik, 1994; Dore et al., 2009), because the genus is not sphereshaped. Moreover, $U_{\text {sink,e }}$ (green line) still overestimated the observed velocity (grey box), because accounting for additional drag from the Daphnia antenna is important when modelling sinking rates (Gorski \& Dodson, 1996; Dore et al., 2009). The good agreement between $U_{\text {sink }}$ and the field data strongly indicates that organisms sank during the DVM because organism's buoyancy and gravity are the only governing parameters of the reverse migration (Ringelberg \& Flik, 1994). Since $v_{\text {down }}$ shows no trend over time (Fig. 4, negative values), no correlation exists between this velocity and any DVM drivers in the field. The only available study for Daphnia by Ringelberg \& Flik (1994) suggests that the genus actively swims only when the light stimulus $S$ is high. According to the meteorological station measurements, zooplankton started migrating several minutes before sunrise when the solar radiation was still zero. This may suggest that $S$ was not a causal factor for active downwards DVM (Ringelberg \& Flik, 1994). However, the distance of the station from the study site might have prevented us from measuring small light changes that could have initiated the DVM.

Our model also shows that the velocity changed very little with the temperature, as seen in Kirillin et al. (2012). This explains why $v_{\text {down }}$ was constant during the observations and did not correlate with $T$. Results from the literature cannot be directly compared with our model and observations because organisms have different lengths or density (i.e. eggs in brood chamber), and experiments were performed under different conditions of $T$.

Since Daphnia always sank during the observational period, our results indicate that these zooplankton may favour passive sinking over active swimming during the reverse DVM to preserve energy and avoid generating hydrodynamic disturbances detectable by predators. 


\section{Conclusions}

In this study, we assessed the mean displacement velocity of zooplankton from the slope of the zooplankton layer during the DVM at sunset and sunrise. This velocity can be used to infer possible changes in zooplankton behaviour during the DVM due to the external and internal drivers. The upward bulk velocity $v_{\text {up }}$ increased over time and was strongly correlated with the water temperature. Based upon our analysis, chlorophyll concentration, relative change of light intensity and zooplankton concentration and size during the DVM did not seem to play an important role in affecting $v_{\text {up }}$. This suggests that temperature may be a key mechanical factor controlling swimming activity. Temperature can increase metabolic rates, and zooplankton require less effort to propel themselves in a less viscous fluid. The relationship between temperature and velocity has, so far, only been demonstrated under greatly simplified conditions in laboratory experiments (Larsen \& Riisgård, 2009). We demonstrate, for the first time, the potential for the same effect to be significant in the field. In the field, it is not, however, possible to separate the direct effect of the temperature (physiological effect) and the indirect impact of viscosity (mechanical effect). Our correlation did not account for any effect due to predation pressure. However, because we did not observe changes in the zooplankton daytime-depth or migration amplitude during the two years, we hypothesise that the intensity of visual predation was consistent throughout our study period and could not explain the changes in migration velocity that occurred. Although predation pressure may be important in determining whether migration happens at all, temperature may be more important in governing migration velocity, when this behaviour does occur. The velocity at sunrise $v_{\text {down }}$ was instead constant. The lack of variation in $v_{\text {down }}$ was likely because Daphnia passively sank instead of swimming during the reverse migration. Our new model of the Daphnia sinking rate confirmed that buoyancy and gravity were the governing parameters of the reverse migration.

Understanding behaviour and responses of diel migrators to exogenous conditions is essential to knowledge of ecosystem functioning. Zooplankton experience varying temperatures in lakes due to shortterm meteorological forcing and seasonality or as a function of the water depth. Varying temperature affects zooplankton metabolism, potentially impacting patterns in excretion and faecal pellet production throughout the water column and altering biogeochemical fluxes of nutrients and carbon. According to our analyses, changes in water temperature and thus viscosity over time impact upward migration velocity and by extension escape velocities from predators: in warmer and less viscous waters, organisms can escape faster and more efficiently, therefore reducing their predation risk. The alteration of predation patterns via this mechanism can indirectly influence trophic interactions and energy flows in lake food webs. Finally, understanding zooplankton behaviour during the reverse migration is equally significant. Organisms may favour passive sinking over active swimming to conserve energy and avoid hydrodynamic disturbances that would be detectable by predators.

Acknowledgements Funding for this work was provided by a UK Royal Society Research Grant (Y0106WAIN) and an EU Marie Curie Career Integration Grant (PCIG14-GA-2013630917) awarded to D. J. Wain. We would also like to thanks Tim Clements for allowing us access to Vobster Quay.

Open Access This article is distributed under the terms of the Creative Commons Attribution 4.0 International License (http:// creativecommons.org/licenses/by/4.0/), which permits unrestricted use, distribution, and reproduction in any medium, provided you give appropriate credit to the original author(s) and the source, provide a link to the Creative Commons license, and indicate if changes were made.

\section{References}

Andersen Borg, C. M., E. Bruno \& T. Kiørboe, 2012. The kinematics of swimming and relocation jumps in Copepod Nauplii. PLoS ONE 7: 33-35.

Armengol, J., L. Caputo, M. Comerma, C. Feijoo, J. C. Garcia, R. Marce, E. Navarro \& J. Ordonez, 2003. Sau reservoir's light climate: relationships between Secchi depth and light extinction coefficient. Limnetica 22: 195-210.

Barth, L. E., W. G. Sprules, M. Wells, M. Coman \& Y. Prairie, 2014. Seasonal changes in the diel vertical migration of Chaoborus punctipennis larval instars. Canadian Journal of Fisheries and Aquatic Sciences 71: 665-674.

Batchelor, G. K., 1959. Small-scale variations of convected quantities like temperature in turbulent fluid. part I: general discussion and the case of small conductivity. Journal of Fluid Mechanics 5: 113-133.

Beck, J. L. \& R. G. Turingan, 2007. The effects of zooplankton swimming behavior on prey-capture kinematics of red 
drum larvae, Sciaenops ocellatus. Marine Biology 151: 1463-1470.

Beklioglu, M., A. G. Gozen, F. Yıldırım, P. Zorlu \& S. Onde, 2008. Impact of food concentration on diel vertical migration behaviour of Daphnia pulex under fish predation risk. Hydrobiologia 614: 321-327.

Beveridge, O. S., O. L. Petchey \& S. Humphries, 2010. Mechanisms of temperature-dependent swimming: the importance of physics, physiology and body size in determining protist swimming speed. Journal of Experimental Biology 213: 4223-4231.

Black, A. R. \& S. I. Dodson, 2003. Ethanol: a better preservation technique for Daphnia. Limnology Oceanography Methods 1: 45-50.

Boeing, W. J., D. M. Leech \& C. E. Williamson, 2003. Opposing predation pressures and induced vertical migration responses in Daphnia. Limnology Oceanography 48: 1306-1311.

Cohen, J. H. \& R. B. Forward, 2009. Zooplankton diel vertical migration - a review of proximate control. Oceanography Marine Biology 47: 77-110.

Daan, N. \& J. Ringelberg, 1969. Further studies on the positive and negative phototactic reaction of Daphnia Magna. Netherlands Journal of Zoology 19: 525-540.

Deines, K., 1999. Backscatter estimation using broadband acoustic Doppler current profilers. Proceedings of the IEEE Sixth Working Conference on Current Measurement (Cat. No.99CH36331)

Dodson, S., 1988. The ecological role of chemical stimuli for the zooplankton: predator-avoidance behavior in Daphnia. Limnology Oceanography 33: 1431-1439.

Dodson, S., 1990. Predicting diel vertical migration of zooplankton. Limnology Oceanography 35: 1195-1200.

Dodson, S. I., T. Hanazato \& P. R. Gorski, 1995. Behavioral responses of Daphnia pulex exposed to carbaryl and Chaoborus kairomone. Environmental Toxicology and Chemistry 14: 43-50.

Dodson, S. I., S. Ryan, R. Tollrian \& W. Lampert, 1997a. Individual swimming behavior of Daphnia: effects of food, light and container size in four clones. Journal of Plankton Research 19: 1537-1552.

Dodson, S. I., R. Tollrian \& W. Lampert, 1997b. Daphnia swimming behavior during vertical migration 19: 969-978.

Dore, V., M. Moroni, M. L. Menach \& A. Cenedese A, 2009. Investigation of penetrative convection in stratified fluids through 3D-PTV. Experiments in Fluids 47: 811-825.

Francois, R. E., 1982. Sound absorption based on ocean measurements: part I: pure water and magnesium sulfate contributions. The Journal of the Acoustical Society of America 72: 896.

Gool, E. V. \& J. Ringelberg, 1995. Swimming of Daphnia galeata $\mathrm{x}$ hyalina in response to changing light intensities: influence of food availability and predator kairomone. Marine and Freshwater Behaviour and Physiology 26: 259-265.

Gorski, P. R. \& S. I. Dodson, 1996. Free-swimming Daphnia pulex can avoid following Stokes law. Limnology Oceanography 41: 1815-1821.

Gries, T., K. Jöhnk, D. Fields \& J. R. Strickler, 1999. Size and structure of 'footprints' produced by Daphnia: impact of animal size and density gradients. Journal of Plankton Research 21: 509-523.

Hays, G. C., 2003. A review of the adaptive significance and ecosystem consequences of zooplankton diel vertical migrations. Hydrobiologia 503: 163-170.

Heinle, D. R., 1969. Temperature and zooplankton. Chesapeake Science 10: 186-209.

Hembre, L. K. \& R. O. Megard, 2003. Seasonal and diel patchiness of a Daphnia population: an acoustic analysis. Limnology Oceanography 48: 2221-2233.

Huber, A. M. R., F. Peeters \& A. Lorke, 2011. Active and passive vertical motion of zooplankton in a lake. Limnology Oceanography 56: 695-706.

Humphries, S., 2013. A physical explanation of the temperature dependence of physiological processes mediated by cilia and flagella. Proceedings of the National Academy of Sciences of the United States of America 36: 14693-14698.

Huntley, M. E. \& M. Zhou, 2004. Influence of animals on turbulence in the sea. Marine Ecology Progress Series 273: 65-79.

Hutchinson, G. E., 1967. A treatise on limnology. Wiley, Hoboken.

Inoue, R., M. Kitamura \& T. Fujiki, 2016. Diel vertical migration of zooplankton at the S1 biogeochemical mooring revealed from acoustic backscattering strength. Journal of Geophysical Research 121: 1031-1050.

Jung, I., T. Powers \& J. Valles Jr., 2014. Evidence for two extremes of ciliary motor response in a single swimming microorganism. Biophysical Journal 106: 1.

Kirillin, G., H. P. Grossart \& K. W. Tang, 2012. Modelling sinking rate of zooplankton carcasses: Effects of stratification and mixing. Limnology Oceanography 57: 881-894.

Larsen, P. S. \& H. U. Riisgård, 2009. Viscosity and not biological mechanisms often controls the effects of temperature on ciliary activity and swimming velocity of small aquatic organisms. Journal of Experimental Marine Biology and Ecology 381: 67-73.

Larsen, P. S., C. V. Madsen \& H. U. Riisgård, 2008. Effect of temperature and viscosity on swimming velocity of the copepod Acartia tonsa, brine shrimp Artemia salina and rotifer Brachionus plicatilis. Aquatic Biology 4: 47-54.

Lass, S. \& P. Spaak, 2003. Chemically induced anti-predator defences in plankton: a review. Hydrobiologia 491: 221-239.

Leach, T. H., C. E. Williamson, N. Theodore, J. M. Fischer \& M. H. Olson, 2014. The role of ultraviolet radiation in the diel vertical migration of zooplankton: an experimental test of the transparency-regulator hypothesis. Journal of Plankton Research 37: 886-896.

Loose, C. J. \& P. Dawidowicz, 1994. Trade-offs in diel vertical migration by zooplankton: the costs of predator avoidance. Ecology 75: 2255-2263.

Lorke, A., D. F. McGinnis, P. Spaak \& A. Wüest, 2004. Acoustic observations of zooplankton in lakes using a Doppler current profiler. Freshwater Biology 49: 1280-1292.

Machemer, H., 1972. Ciliary activity and the origin of metachrony in paramecium: effects of increased viscosity. Journal of Experimental Biology 57: 239-259. 
Michalec, F. G., S. Souissi \& M. Holzner, 2015. Turbulence triggers vigorous swimming but hinders motion strategy in planktonic copepods. Journal of The Royal Society Interface 12: 20150158-20150158.

Moison, M., F. G. Schmitt \& S. Souissi, 2012. Effect of temperature on Temora longicornis swimming behaviour: illustration of seasonal effects in a temperate ecosystem. Aquatic Biology 16: 149-161.

Neill, W. E., 1990. Induced vertical migration in copepods as a defence against invertebrate predation. Nature 345: 524-526.

Paffenhöfer, G. A. \& M. G. Mazzocchi, 2002. On some aspects of the behaviour of Oithona plumifera (Copepoda: Cyclopoida). Journal of Plankton Research 2: 129-135.

Prairie, J. C., K. R. Sutherland, K. J. Nickols \& A. M. Kaltenberg, 2012. Biophysical interactions in the plankton: a cross-scale review. Limnology. Oceanography 2: 121-145.

Record, N. R. \& B. de Young, 2006. Patterns of diel vertical migration of zooplankton in acoustic Doppler velocity and backscatter data on the Newfoundland Shelf. Canadian Journal of Fisheries and Aquatic Sciences 63: 2708-2721.

Ringelberg, J., 1999. The photobehaviour of Daphnia spp. as a model to explain diel vertical migration in zooplankton. Biological Reviews of the Cambridge Philosophical Society 74: 397-423.

Ringelberg, J., 2010. Diel Vertical Migration of Zooplankton in Lakes and Oceans. Springer, Netherlands.

Ringelberg, J. \& B. J. G. Flik, 1994. Increased phototaxis in the field leads to enhanced diel vertical migration. Limnology Oceanography 39: 1855-1864.

Ringelberg, J., B. J. G. Flik, D. Lindenaar \& K. Royackers, 1991. Diel vertical migration of Daphnia hyalina (sensu latiori) in Lake Maarsseveen: part 1. Aspects of seasonal and daily timing. Archiv fur Hydrobiologie 121: 129-145.

Rinke, K. \& T. Petzoldt, 2008. Individual-based simulation of diel vertical migration of Daphnia: a synthesis of proximate and ultimate factors. Limnologica 38: 269-285.

Ruddick, B., A. Anis \& K. Thompson, 2000. Maximum likelihood spectral fitting: the batchelor spectrum. Journal of Atmospheric and Oceanic Technology 17: 1541-1555.

Saiz, E., A. Calbet \& E. Broglio, 2013. Effects of small-scale turbulence on copepods: the case of Oithona davisae. Limnology and Oceangraphy 48: 1304-1311.

Seuront, L., H. Yamazaki \& S. Souissi, 2004. Hydrodynamic disturbance and zooplankton swimming behavior. Zoological Studies 43: 376-387.
Simoncelli, S., S. J. Thackeray \& D. J. Wain, 2018. On biogenic turbulence production and mixing from vertically migrating zooplankton in lakes. Aquatic Science 80: 35.

Sutor, M., T. J. Cowles, W. T. Peterson \& J. Lamb, 2005. Comparison of acoustic and net sampling systems to determine patterns in zooplankton distribution. Journal of Geophysical Research C: Oceans 110: 1-11.

Tiberti, R. \& R. Iacobuzio, 2013. Does the fish presence influence the diurnal vertical distribution of zooplankton in high transparency lakes? Hydrobiologia 709: 27-39.

Van Gool, E., 1997. Light-induced swimming of Daphnia: can laboratory experiments predict diel vertical migration? Hydrobiologia 360: 161-167.

Van Gool, E. \& J. Ringelberg, 1998a. Light-induced migration behaviour of Daphnia modified by food and predator kairomones. Animal behaviour 56: 741-747.

Van Gool, E. \& J. Ringelberg, 1998b. Quantitative effects of fish kairomones and successive light stimuli on downward swimming responses of Daphnia. Aquatic Ecologuy 32: 291-296.

Van Gool, E. \& J. Ringelberg, 2003. What goes down must come up: Symmetry in light-induced migration behaviour of Daphnia. Hydrobiologia 491: 301-307.

Visser, A. W. \& A. Stips, 2002. Turbulence and zooplankton production: insights from PROVESS. Journal of Sea Research 47: 317-329.

Weber, A. \& A. Van Noordwijk, 2002. Swimming behaviour of Daphnia clones: differentiation through predator infochemicals. Journal of Plankton Research 24: 1335-1348.

Webster, D. R., D. L. Young \& J. Yen, 2015. Copepods response to burgers vortex: deconstructing interactions of copepods with turbulence. Integrative and Comparative Biology 55: 706-718.

Wickramarathna, L. N., 2016. Kinematics and Energetics of Swimming Zooplankton. Universität Koblenz-Landau, Mainz.

Wickramarathna, L.N., C. Noss \& A. Lorke, 2014. Hydrodynamic trails produced by Daphnia: size and energetics. PLOS ONE 9

Williamson, C. E., J. M. Fischer, S. M. Bollens, E. P. Overholt \& J. K. Breckenridge, 2011. Towards a more comprehensive theory of zooplankton diel vertical migration: integrating ultraviolet radiation and water transparency into the biotic paradigm. Limnology Oceanography 56: 1603-1623. 